Document downloaded from:

http://hdl.handle.net/10251/49294

This paper must be cited as:

Benajes Calvo, JV.; Molina Alcaide, SA.; Novella Rosa, R.; De Lima Moradell, DA. (2014). Implementation of the Partially Premixed Combustion concept in a 2-stroke HSDI diesel engine fueled with gasoline. Applied Energy. 122:94-111. doi:10.1016/j.apenergy.2014.02.013.

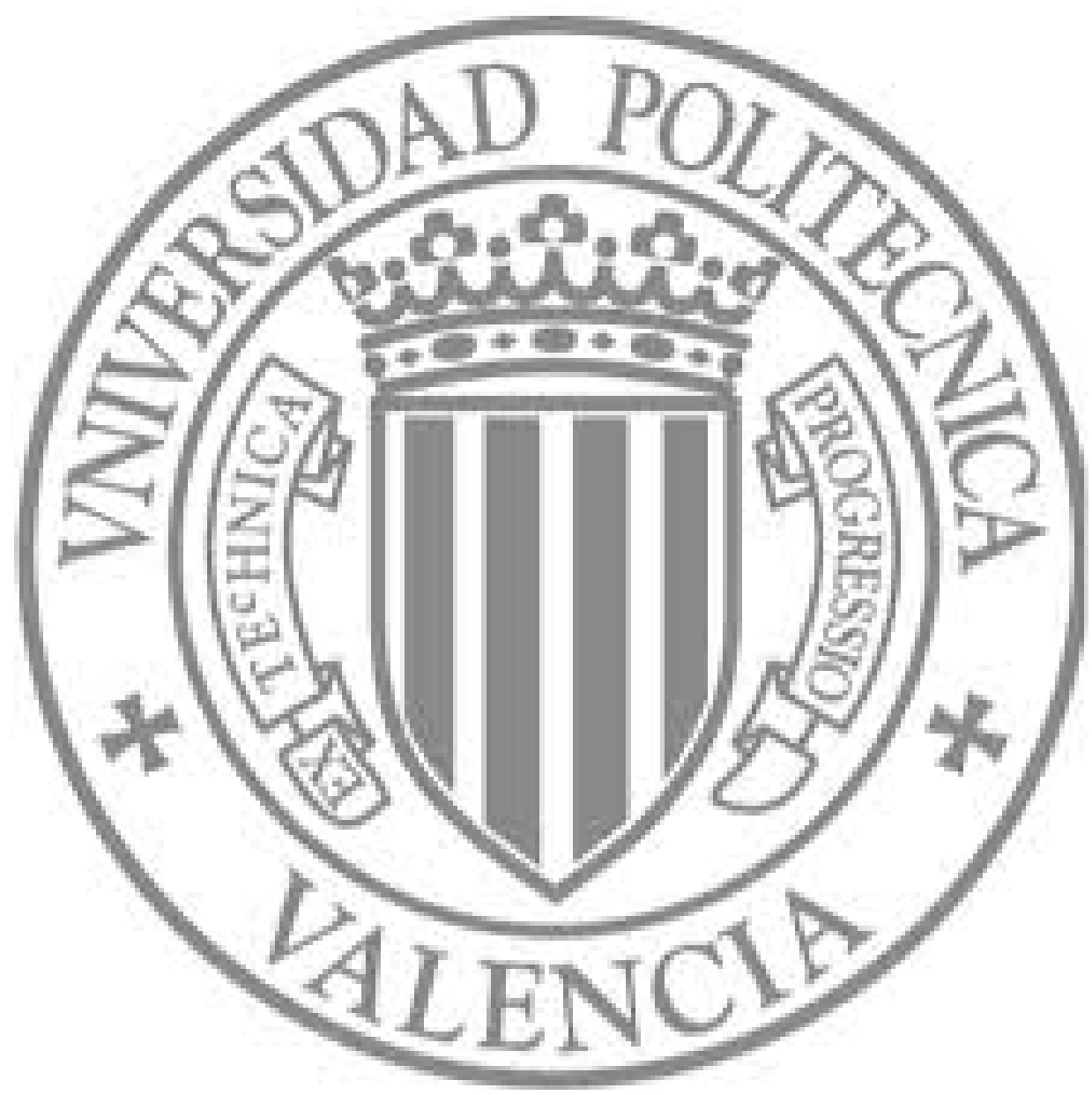

The final publication is available at

http://dx.doi.org/10.1016/j.apenergy.2014.02.013

Copyright Elsevier 


\title{
Implementation of the Partially Premixed Combustion Concept in a 2-stroke HSDI Diesel Engine Fueled with Gasoline
}

\author{
J. Benajes, S. Molina, R. Novella*, D. De Lima \\ CMT-Motores Térmicos \\ Universitat Politècnica de València \\ Camino de Vera s/n, 46022, Valencia (Spain) \\ Tel. (0034) 963877650 / Fax (0034) 963877659
}

\begin{abstract}
Partially Premixed Combustion (PPC) of fuels in the gasoline octane range has proven to combine low $\mathrm{NO}_{\mathrm{X}}$ and soot emissions with high indicated efficiencies, while still retaining control over combustion phasing with the injection event. Previous research performed in four-stroke engines, has shown how the operating region where gasoline PPC concept can be successfully implemented is largely linked to the octane number of the fuel, making difficult to cover the entire load range with a fixed fuel.

In this framework, 2-stroke engines arise as a promising solution to extend the load range of gasoline PPC concept, since it intrinsically provides equivalent torque response with only half the IMEP required in a 4-stroke cycle. Moreover, 2-stroke architecture provides high flexibility on the air management parameters to substantially control the cylinder conditions and affect the combustion environment, allowing proper combustion control even in low load conditions.

An experimental investigation has been performed to evaluate the potential of the PPC concept for pollutant control, using a commercial gasoline with Research Octane Number of 95 in a newly-designed 2-stroke poppet valves automotive diesel engine. The experimental results confirm how it is possible to achieve stable gasoline PPC combustion at a low speed medium load point (1200 rpm, 5 bar IMEP); with good combustion stability ( $\sigma \mathrm{IMEP}$ below 3\%), high combustion efficiency (over 98\%), and low $\mathrm{NO}_{\mathrm{x}}$ and zero soot levels; thanks to the wide control of the cylinder gas temperature provided by the air management settings. Nevertheless, in agreement to the results reported in the literature, the indicated cycle efficiency attained at this low load operating condition is lower than the obtained in conventional diesel combustion conditions. Therefore, a dedicated optimization process of the engine hardware and engine settings is required to fully exploit the benefits of gasoline PPC concept in the investigated 2-stroke engine architecture.
\end{abstract}

Keywords:

2-Stroke Engine, gasoline PPC combustion, Pollutant Emissions, Engine Efficiency

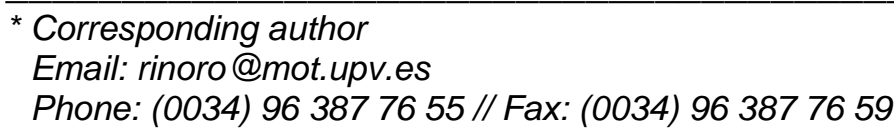


Paper draft:

Implementation of Partially Premixed Combustion in a 2-stroke HSDI diesel engine fueled with gasoline

\section{Introduction}

A relatively new approach, known as Partially Premixed Combustion (PPC), has been designed to operate compression-ignition (CI) engines in between fully premixed combustion and fully diffusive combustion concepts, where low emissions can be still attained while retaining control over the combustion timing with the injection event. The injection process is advanced towards the compression stroke to be detached from the combustion event, enabling partial mixing of the mixture to avoid over-rich regions where soot is formed, whereas $\mathrm{NO}_{\mathrm{x}}$ emissions are reduced by lowering combustion temperatures by introduction of large amounts of EGR [1]. HCCI or PCCI premixed combustion concepts with diesel fuel confirmed how the combustion of a sufficiently premixed cylinder charge is effective for reducing simultaneously $\mathrm{NO}_{\mathrm{x}}$ and soot emissions [2-5]. However, the operating region of this strategy is restricted to low loads due to the strong propensity of auto-igniting the high cetane fuel along the compression stroke [6]. Additionally, $\mathrm{CO}$ and HC emissions sharply increase due to an extremely overmixed mixture and a liquid fuel impinging onto the cylinder walls, which is often unavoidable [7].

Achieving enough mixing time between the end of the injection (EoI) and the start of combustion (SoC) with high cetane diesel fuels requires introducing very large fractions of cooled EGR to slow down the chemical reactions and/or increasing the injection pressure and swirl level to speed up the mixing process. This strategy was implemented by Nissan under the name of Modulated Kinetics (MK) $[8,9]$ and also by Lund University [10]. In both cases, simultaneous reductions in $\mathrm{NO}_{\mathrm{X}}$ and soot emissions were observed for medium-to-high load points. Nevertheless, the range for simultaneous reduction of $\mathrm{NO}_{\mathrm{x}}$ and soot by introducing high EGR rates was very narrow, and a sharp decline in engine efficiency due to high $\mathrm{CO}$ and $\mathrm{HC}$ emissions and poor combustion phasing was observed in most cases [10].

The ignition delay, defined as the difference in crankangle degrees between the start of injection (SoI) and the start of combustion (SoC), can be also extended by using fuels with higher resistance to auto-ignition. Research work performed by Kalghatgi and coworkers in both large [11, 12] and small [13] single-cylinder engines demonstrated how 
Paper draft:

Implementation of Partially Premixed Combustion in a 2-stroke HSDI diesel engine fueled with gasoline

injecting a low cetane fuel such as a gasoline close to (but before) TDC is a suitable option for extending mixing times before the onset of combustion. As a result, a highly premixed combustion process was generated, producing lower engine-out soot and $\mathrm{NO}_{\mathrm{X}}$ emissions than the conventional mixing-controlled diesel diffusive combustion (CDC) in a wider range of engine loads compared to diesel PPC combustion. The authors identified that the mixture stratification on equivalence ratio is mandatory for allowing the control over combustion phasing with the injection timing, as for assuring the ignitability of the cylinder charge.

Results obtained in heavy-duty (HD) 4-stroke diesel engines operating with the PPC combustion concept with gasoline-like fuels and ethanol, respectively in Wisconsin [14] and Lund Universities [15-17], confirmed how it is possible to achieve premixed combustions with very high efficiency, very low $\mathrm{NO}_{\mathrm{X}}$ emissions and lower soot levels compared to those generated by the conventional diesel combustion. However, too low octane fuels presents problems for extending the ignition delay at medium to high engine loads [16]; while too high octane fuels have ignition problems at low engine loads $[18,19]$.

According to the previous considerations, 2-stroke operation is considered as an interesting option to extend the load range of premixed combustions, since it intrinsically provides equivalent torque response with only half the IMEP required in 4stroke operation. With this motivation, an innovative 2-stroke poppet valves HSDI diesel engine is being investigated by the authors for a heavily downsized application, where high power-to-mass ratio is mandatory [20].

Previous research confirmed how the proposed architecture provides high flexibility on the air management parameters to substantially control the cylinder conditions and affect the combustion environment and final emissions levels in conventional diesel combustion [21]. Furthermore, HCCI diesel combustion was implemented and its potential for simultaneous reductions of $\mathrm{NO}_{\mathrm{x}}$ and soot emissions was successfully proven [22]. Nevertheless, the high reactivity of diesel and the high cylinder temperatures caused by the inherently high residual gas fraction made impossible to attain a properly-phased combustion even operating at low loads with optimized engine settings and hardware, so the combustion concept was discarded [23]. 
Additionally, the sharp loss of efficiency of the PPC concept with gasoline-like fuels at medium-to-low loads observed in 4-stroke engines caused by ignition difficulties and high cyclic dispersion (which demands the utilization of gas re-breathing strategies or lower octane fuels), further encouraged the authors to explore the application of the PPC combustion using gasoline-like fuels in this novel 2-stroke engine architecture.

In this framework, the main objective of the present investigation focuses on evaluating the potential of the PPC concept for pollutant control, using a commercial RON 95 gasoline in the 2-stroke poppet valves HSDI diesel engine under development. The proposed 2-stroke architecture is expected to achieve stable PPC combustion at medium and low loads with low cyclic dispersion and high combustion efficiencies, thanks to the wide control of the cylinder gas temperature proportioned by the air management settings. As specific targets, $\mathrm{NO}_{\mathrm{X}}$ emissions should be competitive compared to the levels attained operating in CDC conditions, while achieving extremely low levels of soot emissions and high combustion efficiencies (over 97\%) to maintain CO and HC emissions within acceptable limits. Additionally, high combustion stability, reflected in IMEP coefficient of variation below 5\%, and direct control over the combustion process by the injection event must be retained, so fuel-mixture stratification at the onset of combustion is expected to be needed to assure stable ignition and controlled heat release at every operating condition.

\section{Experimental setup}

\subsection{Engine architecture and hardware}

Experimental activities were performed on a single cylinder research version of a twocylinder 2-stroke HSDI diesel engine with scavenge loop, which is currently under development. As a reference, Table 1 contains the main engine geometrical characteristics of this single-cylinder 2-stroke engine.

The cylinder head has four poppet valves with double-overhead camshafts and a staged roof geometry, specifically designed for baffling the flow of air between the intake and exhaust valves, allowing proper scavenging of the burnt gases but keeping short-circuit losses as low as possible during 2-stroke operation. The definition of the engine architecture, boost system requirements, combustion chamber geometry and scavenging 
Paper draft:

Implementation of Partially Premixed Combustion in a 2-stroke HSDI diesel engine fueled with gasoline

characteristics of this newly designed engine were reported in previous publications [20, 24].

A hydraulic cam-driven Variable Valve Timing system allows delaying intake and exhaust valve timings, departing from the mechanical phasing and up to 30 degrees, as it is shown in Fig. 1. Then, the effective compression ratio, effective expansion ratio and overlap period between intake and exhaust, can be modified by adjusting the valve timing angles as desired, providing great flexibility to substantially modify the cylinder conditions and affect the combustion environment.

The research single cylinder engine is very flexible and parts can be easily interchanged. However, for this first evaluation of the PPC strategy, the engine operates with a conventional diesel piston and common rail HSDI diesel injection system nonoptimized for the strategy. The injector nozzle is equipped with a 10 holes nozzle, with a hole diameter of $80 \mu \mathrm{m}$ to assure good atomization of the fuel and enhance the physical mixing process, and a spray cone angle of $148^{\circ}$ which allows injecting inside the bowl up to -31 cad aTDC.

For the studies performed in this research, a lubricity additive was added to a regular unleaded RON95 gasoline, in an amount corresponding to approximately $30 \mathrm{ppm}$ in volume of the total blend, to secure the proper functioning of the injection system when injecting gasoline. Most important fuel properties are detailed in Table 2. The injector mass flow rate and spray momentum flux were measured at the beginning of this investigation by testing the injection hardware in dedicated test rigs; at a suitable range of operating conditions in terms of injection pressure, injector backpressure and injection duration; following the methodology described in $[25,26]$ using commercial diesel fuel and also the gasoline fuel selected for this research. It was observed that the injection system is able to properly inject gasoline with good performance up to a maximum injection pressure of $1200 \mathrm{bar}$, from where some internal leakages might start to appear and proper functioning of the injection system cannot be further assured.

\subsection{Test cell characteristics}

The engine is assembled into a fully instrumented test cell according to the scheme shown in Fig. 2. Compressed air (oil and water-free) is provided by an external 
Paper draft:

Implementation of Partially Premixed Combustion in a 2-stroke HSDI diesel engine fueled with gasoline

compressor to simulate boost conditions, while the exhaust backpressure is reproduced and controlled by means of a throttle valve placed in the exhaust line after the exhaust settling chamber. The experimental facility also includes a low pressure EGR system, designed to provide arbitrary levels of cooled EGR even at very high intake boost pressures.

Water and oil cooling circuits are also independent from the engine, and temperatures are strictly controlled and monitored during all the experimental tests. The fuel consumption of the engine is measured with a gravimetric dynamic fuel meter.

Pollutant emissions from the engine are sampled close to the exhaust settling chamber and routed to a gas analyzer by a heated pipe to ensure gas temperatures above $150^{\circ} \mathrm{C}$. Measurements of $\mathrm{O}_{2}, \mathrm{CO}, \mathrm{CO}_{2}, \mathrm{HC}, \mathrm{NO} \times, \mathrm{N}_{2} \mathrm{O}$, and EGR rate are performed for all the tests. Soot emissions traced by the filter smoke number (FSN) are measured by an AVL 415 Smokemeter.

The trapping ratio, defined as the mass of delivered charge that has been trapped in the cylinder before combustion divided by the mass of delivered charge supplied to the cylinder (fresh air plus EGR), is experimentally measured in each engine operating point using a tracer gas method [27, 28]. The internal gas recirculation (IGR) ratio is then defined as the fraction of residual gases retained from the previous combustion cycle in the total trapped mass in the cylinder.

The IGR ratio and total trapped mass are estimated in each operating condition using simplified thermodynamic calculations. This estimation is based on an enthalpy balance, where the enthalpy of the total trapped mass at the intake valve closing (IVC) equals to the enthalpy of the residual mass plus the enthalpy of the intake delivered trapped mass (fresh air plus external EGR), both estimated also at the IVC. Finally, the effective in-cylinder air/fuel ratio is calculated from the mass of usable air available in the trapped charge, excluding the air present in the IGR, divided by the injected fuel mass. In-cylinder equivalence ratio is then calculated using the stoichiometric air/fuel ratio and the effective in-cylinder air/fuel ratio.

Cylinder pressure is measured using a piezoelectric sensor, while a different piezorresistive pressure sensor is placed at the cylinder liner close to bottom dead center 
Paper draft:

Implementation of Partially Premixed Combustion in a 2-stroke HSDI diesel engine fueled with gasoline

(BDC) to reference the piezoelectric sensor pressure signal. All high frequency signals are sampled with a resolution of 0.2 cad. Table 3 shows the accuracy of the instrumentation used along the research.

The most relevant global parameters related to the combustion process, such as the indicated mean effective pressure (IMEP), start of combustion (SoC) and combustion phasing (CA10 and CA50), maximum cylinder pressure, pressure gradient and noise, combustion stability, rate of heat release (RoHR) and cylinder mean gas temperature are calculated from the cylinder pressure signal by an in-house 0-dimensional combustion analysis software (“CALMEC”) [29, 30]. The 0-dimensional model simplifies the phenomena occurring inside the engine cylinder, so it does not provide any information related to local thermochemical conditions. However, the values of CA10, CA50, mixing time, defined as the temporal or angular lag between the end of injection and the onset of combustion identified as the time or angle where the combustion starts to release energy, are still valid since they are directly related to the instantaneous evolution of the energy released by the progress of the combustion, which can be obtained with accuracy by resolving the first law of thermodynamics taking the combustion chamber as the control volume independently from the local conditions where this energy is being released. Thus, the analysis performed along this research work considers these values as proper and correct.

Considering local conditions is much more important to calculate the local reaction temperatures with precision. With the aim of performing the analysis of trends on basis of intuitive and easily obtainable parameters, in this work the instantaneous adiabatic reaction temperature $\left(\mathrm{T}_{\mathrm{ad}}\right)$ was defined as the temperature reached by the mixture with equivalence ratio 1 at the instantaneous in-cylinder pressure and temperature. This temperature is calculated following the method described in [31, 32], and it is used as a tracer to identify the trends followed by the local reaction temperatures. This reaction temperature at equivalence ratio 1 should be a suitable tracer since it corresponds to the maximum local temperature attainable inside the cylinder, since air/fuel mixtures at lower or higher local equivalence ratios will reach lower temperatures after reacting than those attained by this air/fuel mixture at equivalence ratio 1 . Therefore, when comparing two tests with different $\mathrm{T}_{\mathrm{ad}}$, the one with higher $\mathrm{T}_{\mathrm{ad}}$ is expected to generate 
Paper draft:

Implementation of Partially Premixed Combustion in a 2-stroke HSDI diesel engine fueled with gasoline

more thermal $\mathrm{NO}_{\mathrm{X}}$ than the other. Final comparison with experimental results confirms this relation at least in qualitative terms. However, the use of advanced modeling tools, such as CFD, is mandatory if the objective is to perform a detailed analysis or more quantitative comparisons in terms of in-cylinder local conditions.

Finally, the spray mixing process in non-reactive conditions has been simulated at selected test points by means of a 1-D free-spray model [33, 34] in order to study qualitatively the spatial distributions of properties within the spray (composition, temperature, ...) as function of time, and gain insight into the relation between mixing and combustion processes. The analysis performed by means of this 1D spray model follows a similar approach than that reported by Musculus et al. using a similar model developed at Sandia NL [35, 36].

In this 1D spray model the main physical properties for the fuel, considering hexadecane as a proper surrogate due to its similarities with diesel fuel in terms of these properties, and for the spray gas surroundings, considered as a perfect mixture of air and exhaust gas in a given ratio provided by the measured EGR rate, were extracted from reliable database sources such as NIST. The injection mass flow rate and the spray momentum flux, which are the boundary conditions at the injection orifice, were obtained by means of an experimental detailed characterization of the performance of the injector used for this research work. Then, they were experimentally available to feed the 1D model. The surrounding gas thermochemical conditions (pressure, temperature, density and composition) were calculated from the experimental results available after testing the engine at the given operating conditions. Therefore, the combustion diagnosis code, based on the first principle of Thermodynamics, was used to obtain the instantaneous evolution of these parameters mainly from the measured incylinder pressure instantaneous profile. Finally, the spray cone angle is the unique calibration parameter of the 1D spray model, and it was estimated from the fuel and surrounding gas conditions adapting the expression suggested by Naber and Siebers [37].

In order to validate the model predictions, the actual spray evolution was characterized by performing dedicated tests installing the injector in a visualization test rig, controlling the injection and surrounding gas according to the experimental setup and 
Paper draft:

Implementation of Partially Premixed Combustion in a 2-stroke HSDI diesel engine fueled with gasoline

methodology described in [38, 39]. Afterwards, recorded images of the spray evolution were processed to obtain an experimental averaged spray angle and penetration profile. Fig. 3 includes the validation of the $1 \mathrm{D}$ spray model against these experiments by comparing the estimated/measured spray cone angles, and finally by introducing the estimated angle and all other boundary conditions to check the estimated/measured spray penetration fit. This Figure shows a good agreement between the experiments and the model predictions. On the light of these results, the authors considered this model suitable for being used to analyze qualitatively the spray mixing evolution along this research work.

\section{Methodology}

The research work, divided in two phases described below, corresponds to preliminary studies of the gasoline PPC concept on the 2-stroke engine, without any in-depth optimization of the engine hardware or settings. The engine operating condition chosen for this experimental test campaign corresponds with a low speed (1200 rpm) and medium load (5 bar of IMEP) point, where the implementation of the PPC concept is achievable and safe for this preliminary stage of the research.

A single injection strategy was used in all studies presented in this research, with a fixed fueling rate which provided 5 bar of IMEP at a CA50 of 5 cad aTDC, for the initial case of study of 600 bar of injection pressure with start of energizing of the injector (SoE) equal to -27 cad aTDC. The timing of the single injection was swept each 2 cad for each study, starting at -31 cad aTDC (earliest possible SoE before targeting the fuel outside the bowl) gradually getting closer to TDC until combustion stability is compromised and misfire cycles starts to appear. Oil and coolant temperatures were maintained constant at $90^{\circ} \mathrm{C}$ while intake air temperature at the surge tank was controlled at $35^{\circ} \mathrm{C}$. Table 4 contains the most relevant test conditions.

For the first stage of this research, the gasoline PCC concept is implemented for two different injection pressures, 400 and 600 bar, without introducing EGR. Afterwards, the maximum EGR percentage allowed before compromising combustion stability was evaluated; firstly, keeping the same air management conditions as in the first stage of implementation; and secondly, with re-defined air management conditions in order to 
Paper draft:

Implementation of Partially Premixed Combustion in a 2-stroke HSDI diesel engine fueled with gasoline

increase cylinder gas temperatures to permit higher EGR rates, and finally achieve the expected low levels of $\mathrm{NO}_{\mathrm{x}}$ and soot emissions. The most relevant engine settings chosen for each parametric variation are detailed in Table 5.

\section{Results and discussion}

\subsection{Implementation of the gasoline PPC concept}

Previous research performed in CDC conditions, showed how the 2-stroke poppet valves architecture inherently exhibits low trapping efficiencies compared to 4-stroke engines, due to the required positive pressure difference between the intake and exhaust $(\Delta \mathrm{P})$, the long overlap duration, and the proximity between intake and exhaust valves (even with masking on the intake). The valve overlap and $\Delta \mathrm{P}$ are the two most important air management settings controlling the cylinder conditions, which are directly linked to the combustion process, the emissions formation and final engine efficiency; so it is highly recommended to perform a dedicated optimization of the air management settings to fully exploit the potential of the 2-stroke architecture [21]. Nevertheless, for this first evaluation of the gasoline PPC concept, the air management settings were chosen based on previous knowledge without performing in-depth optimization, to obtain the required temperature evolution along compression to reach auto-ignition temperature of gasoline (around 950K) near the end of compression stroke and assure the proper ignition of the cylinder charge.

Experimental results demonstrate the small effect of injection settings on air management conditions, reflected in constant values of trapping ratio (66\%) and IGR ratio (39\%) independently from the injection timings and injection pressures. Additionally, most important cylinder gas conditions also remained unaltered regardless of the injection timing or injection pressure. Therefore, the defined air management conditions provided suitable boundary conditions for the combustion process, with incylinder richness $\left(\phi_{\text {cyl }}\right)$ equal to 0.47 , temperature and oxygen concentration at IVC ( $\mathrm{T}_{\mathrm{IVC}}$ and $\mathrm{Y}_{\mathrm{O} 2, \mathrm{IVC}}$ ) of $160^{\circ} \mathrm{C}$ and $19 \%$ respectively, and oxygen concentration at EVO (Y $\left.\mathrm{Y}_{\mathrm{O}, \mathrm{EVO}}\right)$ of $12.3 \%$.

Focusing on combustion process, Fig. 4 shows the cylinder gas mean temperature evolution, cylinder pressure, rate of heat release and injection rate profiles for the two 
Paper draft:

Implementation of Partially Premixed Combustion in a 2-stroke HSDI diesel engine fueled with gasoline

measured injection pressures (400 and 600 bar) at each injection timing. The high level of IGR given by the air management conditions provides suitable $\mathrm{T}_{\text {IVC }}$ to assure reaching auto-ignition conditions of gasoline close to TDC, as shown in Fig. 4.a.

Injection rate and heat release profiles, included in Fig. 4.c, confirm how the injection event is always detached from the combustion process. Then, the mixing time defined as the angle gap between the end of injection and the start of combustion is extended, and the excessively high equivalence ratios are avoided by the relatively long ignition delays. Simultaneously, some degree of mixture stratification is maintained to assure ignition and finally control over the start of combustion and combustion phasing is retained through the injection timing. Thus, gasoline PPC concept is successfully implemented at this operating point.

In general terms, advancing injection timing earlier in the compression stroke (shifting SoE from -23 to -31 cad aTDC) increases peak cylinder pressure, maximum pressure gradient and temperature, and advances combustion phasing as in CDC, until reaching a boundary where highly premixed conditions are attained and combustion is retarded and softened even when the injection timing is advanced. This condition is observed in the point with earliest injection timing and highest injection pressure, SoE -31 cad aTDC and $P_{\text {rail }}$ of 600 bar, where the improved mixing rate and longer mixing times, resulted in an overmixed mixture with less reactive and leaner equivalence ratio distribution at SoC, compromising the control over the onset of combustion and rate of heat release with the injection timing. Fig. 4 and Fig. 5 show how at this condition the maximum cylinder pressure and maximum pressure gradient decrease, combustion phasing delays in the cycle and heat release rate profile indicates a slower combustion rate with a lower maximum value, despite the earlier injection timing.

Comparing both injection pressures, 400 bar presents richer fuel/air local mixtures which are more reactive at the SoC than in the case of 600 bar, providing considerably higher peak cylinder pressures and pressure rise rates, confirmed in Fig. 5, as well as sharper and shorter heat release rate profiles as observed in Fig. 4.c. These differences in reactivity will be confirmed later by the analysis of the results obtained with a dedicated 1D spray mixing model. The points with $\mathrm{P}_{\text {rail }}$ equal to 400 bar and SoE ranging from -27 to -31 cad aTDC, presented the highest pressure rise rates and noise 
Paper draft:

Implementation of Partially Premixed Combustion in a 2-stroke HSDI diesel engine fueled with gasoline

levels (higher than $15 \mathrm{bar} / \mathrm{cad}$ and close to $100 \mathrm{dBA}$ ) of all cases, which indicates abrupt and fast combustions being close to knocking conditions and above the desirable operation range required to assure engine safety and durability. Even when pressure rise rates and noise levels are above than the suitable limits, no pressure oscillations typical of knocking combustion were observed in any of the points, and the common knock intensity indicators were below the threshold of knocking combustion. Additionally, these values are expected to be reduced for subsequent tests when decreasing the reactivity of the mixture by introducing external EGR.

Regarding combustion stability, coefficient of variation of the maximum cylinder pressure $\left(\sigma \mathrm{P}_{\max }\right)$ and coefficient of variation of the IMEP ( $\left.\sigma \mathrm{IMEP}\right)$, shown in Fig. 5.a and Fig. 5.b respectively, were selected as representative of the cycle-to-cycle dispersion. In the case of $\sigma \mathrm{IMEP}$, both injection pressure levels showed fairly a similar IMEP dispersion of around $2 \%$ in all injection timings, which is below the maximum limit of 5\% demanded for passenger comfort. Nevertheless, increasing injection pressure from 400 to 600 bar also increases $\sigma \mathrm{P}_{\max }$ due to leaner and less reactive local fuel/air mixtures at SoC caused by the improved mixing rate and the longer mixing times. A limit was observed in terms of the latest injection timing measured at each injection pressure from which $\sigma \mathrm{P}_{\max }$ increased sharply until reaching a level where cyclic dispersion was too high and misfire cycles started to appear, gradually losing control over combustion stability until eventually combustion itself could not be sustained anymore. This condition is observed at late combustion phasing with CA50 ranging between 5 to $10 \mathrm{cad}$ or even later because combustion process fully takes place at the expansion stroke, where temperature and pressure are both decreasing slowing down chemical reactions. This is the case of SoE -23 cad aTDC and $P_{\text {rail }} 600$ bar, where it was not possible to keep a stable combustion due to the recurrence of misfire cycles.

Results of mixing time and ignition delay are shown in Fig. 6.a. Considerably long ignition delays, over 20 cad in all cases, are attained thanks to the high octane number of gasoline RON95, and delaying the injection timing towards TDC shortens the ignition delay (and mixing time) due to higher mean gas temperatures along the injection event. The onset of combustion is determined by the combination of gas 
Paper draft:

Implementation of Partially Premixed Combustion in a 2-stroke HSDI diesel engine fueled with gasoline

temperature and reactivity of the mixture, reason why combustion starts earlier for $\mathrm{P}_{\text {rail }}$ 400 bar providing shorter ignition delays and mixing times than $P_{\text {rail }} 600$ bar.

Fig. 6.b contains the key combustion phasing angles CA10 and CA50 (angles where $10 \%$ and $50 \%$ of the charge mass has burnt), confirming how the tests with higher injection pressure present delayed combustion phasing due to less reactivity of the better-mixed charge which retarded the onset of combustion. At SoE of -27 cad aTDC, increasing injection pressure from 400 to 600 bar allowed delaying CA10 from -0.8 to 2.2 cad aTDC and CA50 from 0.5 to 5 cad aTDC. Additionally, it is evident also that the injection timing controls combustion phasing, except in the case of -31 cad aTDC and $\mathrm{P}_{\text {rail }} 600$ bar.

The spray mixing process in non-reactive conditions has been simulated using a 1-D free-spray model using the measured injection rate profiles, for the earliest and latest injection timing cases at each level of injection pressure. Fig. 7.a shows the estimated maximum local equivalence ratio as a function of time, referred to the start of injection. The ignition delay for each case is included in this plot as vertical lines. Before the end of the injection event, the maximum local equivalence ratio equals infinite at the nozzle exit, but for convenience, was cut to a maximum value equal to 6. Note how, for both injection pressures at their latest injection timing, SoE -23 cad aTDC and SoE -25 cad aTDC for 400 and 600 bar respectively, the maximum local equivalence ratio descends slightly faster compared to the earliest SoE, as a result of the enhanced mixing processes induced by higher density inside the chamber during injection process; nevertheless, since the ignition delay is shorter for the latest SoE, a shorter mixing time results in slightly higher maximum equivalence ratio at SoC. Comparing between injection pressures, it is evident how the higher $\mathrm{P}_{\text {rail }}$ provides a faster mixing process which added to the extended ignition delay, results in clearly lower maximum equivalence ratio at SoC as expected.

To complement this information, Fig. 7.b shows the estimated fuel distribution at the start of combustion for each injection pressure and its earliest and latest SoE, which has been traced by the percentage of the total injected fuel mass under a given equivalence ratio. Fig. 7.b confirms that for both injection pressures rich combustion zones (above 2 of equivalence ratio) are completely avoided as desired, therefore, no soot formation is 
Paper draft:

Implementation of Partially Premixed Combustion in a 2-stroke HSDI diesel engine fueled with gasoline

expected to occur. In the case of $\mathrm{P}_{\text {rail }} 400 \mathrm{bar}$, advancing the injection timing provides slightly more time to premix the air/fuel mixture, decreasing the percentage of injected fuel mass which is under reactive equivalence ratios (between 1.4 and 0.8), passing from $43 \%$ for the most retarded SoE to $30 \%$ for the earliest SoE. Nevertheless, the conditions where combustion takes place are quite different between both cases since the mixture at SoE -23 cad aTDC is more reactive than at SoE -31 cad aTDC, but combustion starts and progresses along the expansion stroke where pressure and temperature are already decreasing; while in the case of SoE -31 cad aTDC there is still $30 \%$ of fuel mass at reactive equivalence ratios and combustion starts right before TDC where temperature and pressure are increasing, explaining the differences in RoHR profiles observed earlier in Fig. 4.c.

Comparing both injection pressures, Fig. 7.b clearly evidences how the improved mixing conditions added to longer ignition delays and mixing times provided by injecting the fuel at higher injection pressure, allowed decreasing substantially the fuel mass percentage under reactive conditions compared to the lower injection pressure case, going from $43 \%$ to $14 \%$ for the latest SoE and from $30 \%$ to $7 \%$ for the earliest SoE. These differences on fuel mass distribution support the different shapes of RoHR profiles, in terms of duration and maximum peak, observed previously in Fig. 4.c. Finally, the right plot in Fig. 7.b referred to $\mathrm{P}_{\text {rail }}=600$ bar also explains the behavior previously observed in the case of SoE -31 cad aTDC, where the mixture is located at the transition between partially premixed and highly premixed conditions; so there is not enough stratification in equivalence ratios to sustain the control over the onset of combustion with the injection event.

Aside from the previously discussed impact of increasing injection pressure on local mixing conditions and then on combustion characteristics, there should be also some additional effects associated to the increment in spray length. Several authors reported how the core fluid region near the center of the combustion chamber is the hottest zone of the cylinder and the air/fuel mixture gets progressively cooler near the boundaries of the combustion chamber and in the crevices. These temperature gradients naturally occur as a result of heat loss to the cylinder walls, head and piston during the compression stroke [40-42]. The hottest region will ignite first with subsequent ignition 
occurring in colder regions, for instance near to the cylinder walls. Then, in those configurations where the fuel reaches the wall of the cylinder well before ignition, the combustion process can be concentrated closer to the colder regions, and consequently the onset of combustion may trend to be delayed. The effect of increasing spray length when increasing injection pressure is expected to be coupled with that of the local mixing conditions, finally delaying the onset of combustion, as it is observed in the presented results.

Regarding exhaust emissions, Fig. 8.a and Fig. 8.b shows $\mathrm{NO}_{\mathrm{x}}$ and Smoke emissions and $\mathrm{CO}$ and $\mathrm{HC}$ emissions respectively, while Fig. 8.c shows both combustion and indicated cycle efficiency. $\mathrm{NO}_{\mathrm{x}}$ emissions for $\mathrm{P}_{\text {rail }} 400$ bar are considerably above the required levels because of the high temperature gradient caused by the sharp and abrupt combustion close to knocking conditions. Increasing injection pressure helped in decreasing $\mathrm{NO}_{\mathrm{x}}$ emissions in more than $50 \%$, due to the reduction in temperatures thanks to the increment in the fuel mass mixed below the most reactive equivalence ratios and the consequent more controlled and softened combustion rate. Smoke emissions shown in Fig. 8.a remained close to zero as expected, regardless of the injection timing or injection pressure; because soot formation is avoided when maximum equivalence ratios are kept below 2 by the start of combustion, as it was shown in Fig. 7. HC and CO emissions increased with higher injection pressure due to more premixed conditions and lower temperatures, which slightly punished combustion efficiency, as can be seen in Fig. 8.c. Additionally, an increase in CO and HC was also observed in the latest SoE for both $\mathrm{P}_{\text {rail }} 400$ and 600 bar caused by worsened combustion conditions due to delayed combustion phasing, which decreased combustion efficiency and also increased cycle-to-cycle variation.

Finally, in terms of combustion efficiency it is worth to note that high combustion efficiencies are obtained in all cases (above 95\%), which are above the common values reported in the literature for medium-to-low loads and high octane fuels. Regarding indicated efficiency, values of $40 \%$ are obtained with $\mathrm{P}_{\text {rail }} 600$ bar while lower values (between 37\% and 39\%) were obtained with $\mathrm{P}_{\text {rail }} 400$ bar. The worsened indicated efficiency observed with lower injection pressure might be linked to the combination of too early (and less optimum) combustion phasing and higher heat transfer and friction 
Paper draft:

Implementation of Partially Premixed Combustion in a 2-stroke HSDI diesel engine fueled with gasoline

losses, caused by the increase in temperatures and peak pressures observed when approaching knocking-like conditions.

Moreover, the indicated efficiencies measured in all points are substantially lower than the values reported on the literature (around 45\% to 46\%) on light-duty engines running on PPC combustion at this load condition with lower octane gasoline (from RON70 to RON89) [18]. The observed differences are explained by the intrinsically higher heat transfer losses caused by higher mean cylinder gas temperatures along the closed cycle, induced by the high IGR rate (39\%) required to assure auto-ignition of a higher octane (RON95) gasoline at this low load condition.

\subsection{Effect of external EGR.}

Departing from the results obtained after the implementation of the gasoline PPC strategy, the effect of introducing cooled external EGR to reduce oxygen concentration and decrease mixture reactivity was evaluated along the second stage of the research. The aim of this stage of the research was to find the limit in terms of maximum EGR allowed without compromising combustion stability and combustion control, to achieve the required reduction in $\mathrm{NO}_{\mathrm{X}}$ emissions, while simultaneously maintaining near zero soot emissions and combustion efficiency over $97 \%$. The lowest injection pressure $\left(\mathrm{P}_{\text {rail }}\right.$ 400 bar) provided higher mixture reactivity at SoC and more stratification on equivalence ratio, therefore, it was chosen for the subsequent studies (as shown in Table 5) because it is expected to provide higher tolerance to EGR rate while retaining acceptable combustion stability.

\subsubsection{Constant air management conditions:}

Keeping the same air management conditions than those previously defined ( $\mathrm{P}_{\text {in }} 1.8$ bar, $\mathrm{P}_{\mathrm{ex}} 1.55$ bar and overlap $80 \mathrm{cad}$ ) and fixing a limit of $3 \%$ in terms of maximum acceptable $\sigma \mathrm{IMEP}$, it was only possible to introduce $14 \%$ of external cooled EGR since higher levels caused excessively high cycle-to-cycle dispersion which narrowed the range of operation in terms of SoI due to misfiring problems at the latest injection timings. These test conditions were then kept to evaluate the isolated effect of EGR compared to the reference case without EGR. 
Paper draft:

Implementation of Partially Premixed Combustion in a 2-stroke HSDI diesel engine fueled with gasoline

Starting with the key air management parameters, trapping ratio and IGR ratio remained fairly constant (66\% and 39\%) when introducing 14\% of EGR compared to the reference case without EGR, therefore, $\mathrm{T}_{\text {IVC }}$ was kept at $160^{\circ} \mathrm{C}$ since the scavenging process was not affected by the introduction of EGR. On the counterpart, the in-cylinder equivalence ratio was increased from 0.47 to 0.52 , while $Y_{\mathrm{O} \text {,IVC }}$ decreased from $19 \%$ to $17.7 \%$ and $\mathrm{Y}_{\mathrm{O} 2 \text {,EVC }}$ from $12.3 \%$ to $11.1 \%$.

Instantaneous mean gas temperature, pressure and RoHR profiles are shown in Fig. 9 for the earliest and latest common measured SoE. The straight effect of lowering mixture reactivity when decreasing oxygen concentration by the introduction of EGR $14 \%$ consists of delaying combustion phasing with softened and wider rate of heat release, lower maximum cylinder pressure and lower pressure rise rate, as it is shown in Fig. 9 and Fig. 10. The effect of EGR 14\% is more pronounced when combustion takes place along expansion stroke, as in the case of the latest injection timing (SoE -25 cad aTDC) shown in Fig. 9, where combustion becomes highly sensitive to variations in mixture reactivity and gas temperature.

Cycle-to-cycle dispersion remains approximately constant when introducing EGR 14\% in the case of early injection timing points, maintaining both $\sigma \mathrm{IMEP}$ and $\sigma \mathrm{P}_{\max }$ below 3\% as shown in Fig. 10. Nevertheless, when SoE is delayed to -25 cad aTDC combustion becomes unstable and $\sigma \mathrm{P}_{\max }$ is increased up to $7.2 \%$; so retarding injection timing beyond this SoE was not possible due to the appearance of misfire cycles and subsequent loss of combustion. Fig. 11.a illustrates how mixing time and ignition delay were extended introducing EGR 14\% in approximately 2 cad for the advanced injection timing and in around 5 cad for retarded injection timing due to delayed onset of combustion. Accordingly, Fig. 11.b shows how CA10 was shifted towards TDC approximately in the same proportion as the increment in ignition delay, 2 cad for advanced SoE and 5 cad for retarded SoE, while CA50 was delayed 2.5 cad for advanced SoE and 7.6 cad for retarded SoE due to lower combustion rate and its longer duration.

Mixing rate was not significantly affected when introducing EGR 14\%, as can be observed in Fig. 12.a, since the reduction in oxygen concentration was not too high (from 19\% to $17.7 \%$ ), and keeping the same air management conditions allowed 
Paper draft:

Implementation of Partially Premixed Combustion in a 2-stroke HSDI diesel engine fueled with gasoline

keeping constant the total trapped mass, and more importantly, the cylinder density compared to the reference case without EGR. The slightly longer ignition delay observed with EGR provided more time to premix the air/fuel mixture, resulting in a slightly leaner and less reactive mixture at the SoC, as reflected in the fuel/equivalence ratio distribution shown in Fig. 12.b.

Reducing oxygen concentration has a visible impact on combustion temperatures and consequently in $\mathrm{NO}_{\mathrm{x}}$ formation. The adiabatic temperature (denoted as $\mathrm{T}_{\mathrm{ad}}$ ) reached by the mixture at equivalence ratio 1 at the instantaneous in-cylinder pressure and temperature was chosen as a tracer to qualitatively identify the trends followed by the local reaction temperatures. Fig. 13.a shows the instantaneous $T_{\text {ad }}$ for cases without EGR and with EGR 14\% with injection timing at SoE -25 cad aTDC, while Fig. 13.b shows $\mathrm{T}_{\mathrm{ad} \text {,max }}$ against $\mathrm{NO}_{\mathrm{X}}$ emissions. Introducing EGR $14 \%$ helps to decrease $\mathrm{NO}_{\mathrm{X}}$ emissions due to the reduction in $\mathrm{T}_{\mathrm{ad}, \max }$, which decreases from $2580 \mathrm{~K}$ to $2460 \mathrm{~K}$ in the particular case of SoE -25 cad aTDC. Nevertheless, $T_{\text {ad,max }}$ has to be decreased below $2200 \mathrm{~K}$ to fully avoid $\mathrm{NO}_{\mathrm{x}}$ thermal formation mechanisms and therefore, the oxygen concentration has to be lowered furthermore to achieve the expected near-zero values of NOx emissions.

The lower $\mathrm{T}_{\text {ad }}$ when introducing EGR 14\% explains the reduction in $\mathrm{NO}_{\mathrm{x}}$ emissions by half the values previously obtained at the reference case without EGR, as can be seen in Fig. 14.a. Soot emissions are still at zero level thanks to the lack of rich areas of equivalence ratio over 2, while CO and HC emissions, shown in Fig. 14.b, slightly increase for the earliest SoE due to higher fuel overmixing resulting from longer mixing times, and also the worsened oxidation process caused by lower combustion temperatures. Finally, Fig. 14.c shows how combustion efficiency is kept at levels above $97 \%$ for the earliest SoE, while indicated efficiency is slightly increased due to improved combustion phasing and lowered heat transfer losses given by smother RoHR profile, but it is still lower than the values attained with the CDC concept. In the case of the latest SoE (-25 cad aTDC) combustion efficiency falls to 95\% due to late combustion phasing and increased cyclic dispersion, which is reflected in higher levels of CO and HC emissions, as seen in Fig. 14.b. 
Paper draft:

Implementation of Partially Premixed Combustion in a 2-stroke HSDI diesel engine fueled with gasoline

\subsubsection{Re-defined air management conditions:}

Achieving the required low $\mathrm{NO}_{\mathrm{X}}$ levels demands further decrease of oxygen concentration by introducing a higher EGR percentage compared to the previous case, whereas combustion stability has to be maintained at reasonable levels with $\sigma$ IMEP below $3 \%$. Therefore, to be able to keep proper combustion stability while decreasing oxygen concentration, it was necessary to re-adjust air management conditions to increase the gas temperature along compression and assure the auto-ignition of a less reactive cylinder charge. This intrinsic characteristic of the 2-stroke architecture offers high flexibility to control cylinder conditions (gas composition and temperature) and assure stable combustion even at low loads, where auto-ignition of high octane fuel is critical.

Decreasing $\Delta \mathrm{P}$ from 0.25 to 0.2 bar and reducing valve overlap from 80 to $70 \mathrm{cad}$, as can be seen in Table 5, increases trapping ratio from $66 \%$ to $75 \%$ due to lower shortcircuit losses, and also increases IGR ratio from $39 \%$ to $50 \%$ as a consequence of worsened scavenging process. It is important to recall how the total trapped mass is a result of the addition of the delivered trapped mass (defined as the product between the intake air flow including EGR and the trapping ratio) and the mass of residual gases; reason why a higher value of trapping ratio does not necessarily translates into higher total trapped mass.

The increase in IGR ratio was reflected in a rise in $\mathrm{T}_{\text {IVC }}$ from $160^{\circ} \mathrm{C}$ to $245^{\circ} \mathrm{C}$, which allowed introducing 25\% of EGR while still retaining reasonable cycle-to-cycle dispersion. Moreover, $\phi_{\text {cyl }}$ was increased from 0.47 for the case without EGR to approximately 0.9 in the case of EGR 25\%. As a consequence of the lower fresh air mass trapped and lower total trapped mass, $\mathrm{YO}_{2, \mathrm{IVC}}$ is drastically reduced when introducing EGR 25\%, passing from 19\% to 11\%, while $\mathrm{Y}_{\mathrm{O} \text {,EVC }}$ is consequently decreased from $12.3 \%$ to $2.9 \%$.

Regarding combustion characteristics, Fig. 15 shows the instantaneous mean gas temperature, cylinder pressure profile and rate of heat release for the case of EGR 25\% with re-defined air management conditions compared to the reference case without EGR, for the earliest (-31 cad aTDC) and latest (-25 cad aTDC) common injection 
Paper draft:

Implementation of Partially Premixed Combustion in a 2-stroke HSDI diesel engine fueled with gasoline

timings. For EGR 25\%, Fig. 15.a shows the increase in $\mathrm{T}_{\text {IVC, }}$, which is translated into higher temperatures along compression necessary to achieve auto-ignition. Fig. 15.b shows how the cylinder pressure is decreased along the compression stroke due to the lower effective compression ratio (intake valve closes 10 cad closer to TDC) and lower total mass trapped. Moreover, combustion develops later in the cycle (after TDC) with a lower peak of heat release due to lower oxygen concentration given by the higher EGR rate. Furthermore, the mean temperature rise during combustion is higher in the case of EGR 25\% because of lower trapped mass and global equivalence ratio close to stoichiometric compared to the reference case. The higher temperatures observed along the expansion stroke are expected to increase heat transfer losses, impacting negatively the indicated efficiency.

As observed in the cylinder pressure profile, Fig. 16 confirms how the maximum pressure and maximum pressure gradients are decreased in the case of EGR 25\% due to delayed combustion phasing and smother heat release profile, reaching values of pressure rise rate around $10 \mathrm{bar} / \mathrm{cad}$, which are more reasonable for assuring engine durability. Furthermore, the increase in temperatures given by the re-adjusted cylinder conditions helped to keep both $\sigma \mathrm{IMEP}$ and $\sigma \mathrm{P}_{\max }$ below $5 \%$, fulfilling the required limit in cycle dispersion. Finally, the lower oxygen concentration for EGR 25\% retarded combustion phasing after TDC as observed in the RoHR, which resulted in longer ignition delays and extended mixing times as well as later CA10 and CA50, as shown in Fig. 17. By re-adjusting the air management settings, properly phased combustion was achieved with a CA50 around 5 cad aTDC with reasonable pressure rise rate and noise level, while simultaneously retaining the required low cyclic dispersion.

Focusing on the mixing process, Fig. 18.a shows how the mixing rate is substantially slowed down for EGR 25\% as a result of lower cylinder density due to the lower total trapped mass. The worsened mixing conditions explains why the maximum equivalence ratio at SoC remains slightly richer in the case of EGR 25\%, even when the ignition delay was increased compared to the reference case without EGR. As a consequence, a higher percentage of fuel is locally mixed at the most reactive equivalence ratios (between 0.8 and 1.4), as shown in Fig. 18.b, but in a lower oxygen concentration 
Paper draft:

Implementation of Partially Premixed Combustion in a 2-stroke HSDI diesel engine fueled with gasoline

environment. Even so, the maximum equivalence ratio remains below 2 avoiding the soot formation region.

As expected, a drastic reduction in $\mathrm{T}_{\mathrm{ad}}$ is achieved for EGR 25\%, as confirmed by Fig. 19.a and Fig. 19.b. $T_{\text {ad.max }}$ is accordingly decreased below $2200 \mathrm{~K}$, so the thermal path of $\mathrm{NO}_{\mathrm{x}}$ formation is mostly avoided, but it is still high enough to assure $\mathrm{CO}$ oxidation and complete combustion process. Fig. 20.a confirms how $\mathrm{NO}_{\mathrm{X}}$ emissions are successfully decreased to near zero levels, while soot formation is still avoided. Fig. 20.b shows how HC and CO emissions were kept approximately constant or slightly increased in some points compared to the reference case. However, high combustion efficiency (around 98\%) is observed in all cases, which is difficult to achieve in 4-stroke engines at low loads using high octane fuels $[17,18]$. Finally, the differences in the thermodynamic cycle configuration, the deterioration of the gas adiabatic coefficient (higher burnt gas fraction) and the higher heat transfer losses caused by the higher mean gas temperatures along the cycle worsened the indicated efficiency, which dropped from $37 \%$ in the case with no EGR to 35\%, as shown in Fig. 20.c, despite of the improved combustion phasing. The worsening in indicated efficiency observed when low $\mathrm{NO}_{\mathrm{X}}$ and low soot conditions are attained is directly translated in a rise in indicated specific fuel consumption (isfc) in all the measured points with 25\% of EGR.

Furthermore, since the two-cylinder engine concept presents a double stage supercharging system, with a mechanical volumetric charger set downstream to a wastegate turbocharger, it is valuable to estimate by simple thermodynamic calculations the compression work needed to achieve the required intake boost pressure and air flow rate, to obtain an approximation of the expected or "corrected" indicated specific fuel consumption (isf $\mathrm{c}_{\mathrm{corr}}$ ) of the two-cylinder engine at equivalent test conditions.

Comparing the two points with SoE equal to -25 cad aTDC, measured isfc increased from $223 \mathrm{~g} / \mathrm{kWh}$ to $240 \mathrm{~g} / \mathrm{kWh}(+7.6 \%)$ when introducing $25 \%$ of EGR due to the observed reduction in indicated efficiency. However, the estimated isf $\mathrm{c}_{\mathrm{corr}}$ decreased from $270 \mathrm{~g} / \mathrm{kWh}$ to $263 \mathrm{~g} / \mathrm{kWh}(-2.6 \%)$ due to lower air flow rates and higher temperatures at the inlet of the turbine given by the re-defined air management conditions. In general terms, the isf $\mathrm{c}_{\mathrm{corr}}$ appears as a compromise between the compression work demanded by the turbocharger/supercharger devices to achieve the 
required air management conditions and the initial engine efficiency (isfc). In the cases with re-defined air management conditions, the increase in isfc is compensated by the gain in terms of lower compression work, explaining the observed reduction in isf $\mathrm{c}_{\text {corr. }}$.

Finally, the differences between isfc and isf $\mathrm{c}_{\text {corr }}$ were kept in the range of those observed operating with conventional diesel combustion since this PPC concept was implemented defining the air management conditions in order to avoid very high pressure ratios or excessively high air flow rates, which are out of the scope of the practical implementation.

\section{Conclusions}

The present research has been focused on evaluating the performance of the PPC concept for pollutant control, using a commercial RON 95 gasoline in a 2-stroke poppet valves HSDI diesel engine. The 2-stroke architecture under development offers higher flexibility to operate over the air management settings (valve timings and overlap period, intake pressure, pressure drop across the engine and EGR) compared to conventional 4-stroke engines. Then, in-cylinder conditions (composition and temperature) were adjusted to control the onset of combustion in PPC conditions, assuring suitable combustion stability and high combustion efficiencies. This experimental investigation confirms how the PPC concept was successfully implemented attaining low NOx and low soot emission levels in a low load point using high ON commercial gasoline, which is difficult to achieve in 4-stroke engines without the utilization of dedicated re-breathing or negative valve overlap strategies. The following main conclusions were extracted from this research work:

- At constant air management conditions, increasing injection pressure allowed increasing the mixing rate and mixing times, shifting the fuel mass distribution at SoC towards leaner local equivalence ratios, which consequently decreased mixture reactivity. Hence, the onset of combustion was retarded, pressure rise rate was reduced and the rate of heat release was softened compared with the lower injection pressure case. This trend is clearly opposite than that observed in CDC conditions, where increasing injection pressure shortens combustion duration and increases the maximum rate of heat release. 
- It was necessary to match cylinder temperature, oxygen concentration and mixing rate to achieve stable gasoline PPC combustion at a given set of air management conditions. At constant air management settings (meaning approximately constant temperature profile evolution) a lower limit in mixture reactivity appeared, from where combustion could not be sustained without punishing cyclic dispersion. This was translated in a maximum EGR rate, or a maximum injection pressure, that could be used for a given set of air management conditions. If the mixture reactivity was lowered below this limit, combustion stability was lost, and it was necessary to re-adjust the air management conditions to increase cylinder temperature and compensate for the reduction in reactivity.

- Decreasing oxygen concentration by introducing EGR helped as expected in increasing both ignition delay and mixing times, delaying the onset of combustion and its phasing, decreasing both maximum pressure and pressure rise rate, and softening the shape of the heat release.

- Furthermore, to achieve the low $\mathrm{NO}_{\mathrm{x}}$ gasoline PPC concept, it was necessary to introduce moderate percentages of EGR to be able to decrease the maximum combustion temperatures below $2200 \mathrm{~K}$, avoiding $\mathrm{NO}_{\mathrm{X}}$ formation. Soot formation was hindered by maintaining maximum equivalence ratio below 2, which was achieved by detaching the injection and combustion events. In this particular operating condition, it was necessary to introduce EGR 25\% and retain IGR 50\% to achieve low $\mathrm{NOx}$ conditions while assuring a stable wellphased combustion with $\sigma$ IMEP around $2 \%$.

- According to the results reported in the literature, the indicated cycle efficiency at this low load operating condition is lower than the obtained in conventional diesel combustion conditions, therefore, a dedicated optimization process of the engine hardware and engine settings is required to fully exploit the benefits of gasoline PPC concept.

Finally, the proposed strategies to improve the performance of the gasoline PPC concept in a future research comprises: performing multiple injection strategies, increasing the geometric compression ratio or lowering the fuel octane number, and using the intake 
temperature combined with the IGR ratio as levers to control the combustion onset. Furthermore, the gasoline PPC strategy is known to provide the best efficiency results at higher load points, were the advantages over conventional diesel combustion are more evident, therefore it is convenient to evaluate the performance of the gasoline PPC concept in a higher load range.

\section{Acknowledgments}

The authors of this paper thank the Spanish Ministry of Economy and Competitiveness for the financial support of this research through the Project TRA 2010-20271 (LOWTECOM).

The authors kindly recognize the technical support provided by Mr. Pascal Tribotte from RENAULT SAS in the frame of the DREAM-DELTA-68530-13-3205 Project. 
Paper draft:

Implementation of Partially Premixed Combustion in a 2-stroke HSDI diesel engine fueled with gasoline

\section{References}

[1] Okude K, Mori K, Shiino S, Moriya T. Premixed Compression Ignition (PCI) Combustion for Simultaneous Reduction of NOx and soot in Diesel Engine. SAE Technical Paper 2004-011907; 2004.

[2] Takeda Y, Keiichi N, Keiichi N. Emission Characteristics of Premixed Lean Diesel Combustion with Extremely Early Staged Fuel Injection. SAE Technical Paper 961163; 1996.

[3] Walter B, Gatellier B. Development of the High Power NADITM Concept Using Dual Mode Diesel Combustion to Achieve Zero NOx and Particulate Emissions. SAE Technical Paper 2002-01-1744; 2002.

[4] Ryo H, Hiromichi Y. HCCI Combustion in a DI Diesel engine. SAE Technical Paper 200301-0745; 2003.

[5] Hardy WL, Reitz RD. A Study of the Effects of High EGR, High Equivalence Ratio, and Mixing Time on Emissions Levels in a Heavy-Duty Diesel Engine for PCCI Combustion. SAE Technical Paper 2006-01-0026; 2006.

[6] Torregrosa AJ, Broatch A, García A, Mónico LF. Sensitivity of combustion noise and NOx and soot emissions to pilot injection in PCCI Diesel engines. Appl Energy 2013;104:149-57.

[7] Machrafi H, Cavadias S, Amouroux J. A parametric study on the emissions from an HCCI alternative combustion engine resulting from the auto-ignition of primary reference fuels. Appl Energy 2008;85:755-64.

[8] Kimura S, Aoki O, Ogawa H, Muranaka S, Enomoto Y. New Combustion Concept for Ultra-Clean and High-Efficiency Small DI Diesel Engines. SAE Technical Paper 1999-01-3681; 1999.

[9] Kimura S, Aoki O, Kitahara Y, Aiyoshizawa E. Ultra-Clean Combustion Technology Combining a Low-Temperature and Premixed Combustion Concept for Meeting Future Emission Standards. SAE Technical Paper 2001-01-0200; 2001.

[10] Noehre C, Andersson M, Johansson B, Hultqvist A. Characterization of Partially Premixed Combustion. SAE Technical Paper 2006-01-3412; 2006.

[11] Kalghatgi GT, Risberg P, Ångström H-E. Advantages of Fuels with High Resistance to Auto-ignition in Late-injection, Low-temperature, Compression Ignition Combustion. SAE Technical Paper 2006-01-3385; 2006.

[12] Kalghatgi GT, Risberg P, Ångström H-E. Partially Pre-Mixed Auto-Ignition of Gasoline to Attain Low Smoke and Low NOx at High Load in a Compression Ignition Engine and Comparison with a Diesel Fuel. SAE Technical Paper 2007-01-0006; 2007.

[13] Hildingsson L, Kalghatgi G, Tait N, Johansson B, Harrison A. Fuel Octane Effects in the Partially Premixed Combustion Regime in Compression Ignition Engines. SAE Technical Paper 2009-01-2648; 2009.

[14] Hanson R, Splitter D, Reitz R. Operating a Heavy-Duty Direct-Injection CompressionIgnition Engine with Gasoline for Low Emissions. SAE Technical Paper 2009-01-1442; 2009.

[15] Manente V, Johansson B, Tunestal P, Cannella W. Effects of Different Type of Gasoline Fuels on Heavy Duty Partially Premixed Combustion. SAE Int J Engines 2010;2:71-88.

[16] Manente V, Tunestal P, Johansson B. Effects of Ethanol and Different Type of Gasoline Fuels on Partially Premixed Combustion from Low to High Load. SAE Technical Paper 201001-0871; 2010.

[17] Lewander M, Johansson B, Tunestål P. Investigation and Comparison of Multi Cylinder Partially Premixed Combustion Characteristics for Diesel and Gasoline Fuels. SAE Technical Paper 2011-01-1811; 2011.

[18] Solaka H, Aronsson U, Tuner M, Johansson B. Investigation of Partially Premixed Combustion Characteristics in Low Load Range with Regards to Fuel Octane Number in a Light-Duty Diesel Engine. SAE Technical Paper 2012-01-0684; 2012.

[19] Borgqvist P, Tunestal P, Johansson B. Gasoline Partially Premixed Combustion in a Light 
Paper draft:

Implementation of Partially Premixed Combustion in a 2-stroke HSDI diesel engine fueled with gasoline

Duty Engine at Low Load and Idle Operating Conditions. SAE Technical Paper 2012-01-0687; 2012.

[20] Tribotte P, Ravet F, Dugue V, Obernesser P, Quechon N, Benajes J, et al. Two Strokes Diesel Engine - Promising Solution to Reduce CO2 Emissions. Procedia - Social and Behavioral Sciences 2012;48:2295-314.

[21] Benajes J, Novella R, De Lima D, Tribotte P, Quechon N, Obernesser P, et al. Analysis of the combustion process, pollutant emissions and efficiency of an innovative 2-stroke HSDI engine designed for automotive applications. Appl Therm Eng 2013;58:181-93.

[22] Benajes J, Novella R, De Lima D, Dugue V, Quechon N. The potential of highly premixed combustion for pollutant control in an automotive two-stroke HSDI diesel engine. SAE Technical Paper 2012-01-1104; 2012.

[23] Benajes J, Novella R, De Lima D, Quechon N, Obernesser P. Implementation of the early injection highly premixed combustion concept in a two-stroke HSDI engine. SIA Diesel Powertrain Congress 2012, France, June 5-6; 2012.

[24] Pohorelsky L, Brynych P, Macek J, Vallaude P-Y, Ricaud J-C, Obernesser P, et al. Air System Conception for a Downsized Two-Stroke Diesel Engine. SAE Technical Paper 2012-010831; 2012.

[25] Payri R, Salvador FJ, Gimeno J, Bracho G. A new methodology for correcting the signal cumulative phenomenon on injection rate measurements. Exp Tech 2008;32:46-9.

[26] Payri R, García JM, Salvador F, Gimeno J. Using spray momentum flux measurements to understand the influence of diesel nozzle geometry on spray characteristics. Fuel 2005;84:55161.

[27] Olsen D, Hutcherson G, Wilson B, Mitchell C. Development of the Tracer Gas Method for Large Bore Natural Gas Engines: Part 1 - Method Validation. J Eng Gas Turbines Power 2002;124:678-85.

[28] Olsen D, Hutcherson G, Wilson B, Mitchell C. Development of the Tracer Gas Method for Large Bore Natural Gas Engines: Part 2 - Measurement of Scavenging Parameters. J Eng Gas Turbines Power 2002;124:686-94.

[29] Lapuerta M, Armas O, Hernández JJ. Diagnosis of DI Diesel combustion from in-cylinder pressure signal by estimation of mean thermodynamic properties of the gas. Appl Therm Eng 1999;19:513-29.

[30] Payri F, Molina S, Martín J, Armas O. Influence of measurement errors and estimated parameters on combustion diagnosis. Appl Therm Eng 2006;26:226-36.

[31] Benajes J, Novella R, García A, Arthozoul S. The role of in-cylinder gas density and oxygen concentration on late spray mixing and soot oxidation processes. Energy 2011;36:1599611.

[32] Way R. Methods for determination of composition and thermodynamic properties of combustion products for internal combustion engine calculations. Proceedings of the Institution of Mechanical Engineers 1976;190:686-97.

[33] Pastor JV, Javier López J, García JM, Pastor JM. A 1D model for the description of mixing-controlled inert diesel sprays. Fuel 2008;87:2871-85.

[34] Desantes JM, Pastor JV, García-Oliver JM, Pastor JM. A 1D model for the description of mixing-controlled reacting diesel sprays. Combust Flame 2009;156:234-49.

[35] Musculus MPB, Kattke K. Entrainment Waves in Diesel Jets. SAE Technical Paper 200901-1355; 2009.

[36] Musculus MPB, Miles PC, Pickett LM. Conceptual models for partially premixed lowtemperature diesel combustion. Prog Energy Combust Sci 2013;39:246-83.

[37] Naber JD, Siebers DL. Effects of Gas Density and Vaporization on Penetration and Dispersion of Diesel Sprays. SAE Technical Paper 960034; 1996.

[38] Payri R, Salvador FJ, Gimeno J, Novella R. Flow regime effects on non-cavitating injection nozzles over spray behavior. Int J Heat Fluid Flow 2011;32:273-84. 
Paper draft:

Implementation of Partially Premixed Combustion in a 2-stroke HSDI diesel engine fueled with gasoline

[39] Desantes JM, Payri R, Pastor JM, Gimeno J. Experimental characterization of internal nozzle flow and diesel spray behavior. Part I: Non evaporative conditions. Atomization Sprays 2005;15:489-516.

[40] Saxena S, Bedoya ID. Fundamental phenomena affecting low temperature combustion and HCCI engines, high load limits and strategies for extending these limits. Prog Energy Combust Sci 2013;39:457-88.

[41] Herold RE, Krasselt JM, Foster DE, Ghandhi JB, Reuss DL, Najt PM. Investigations into the Effects of Thermal and Compositional Stratification on HCCI Combustion - Part II: Optical Engine Results. SAE Int J Engines 2009;2:1034-53.

[42] Dec JE, Hwang W, Sjöberg M. An Investigation of Thermal Stratification in HCCI Engines Using Chemiluminescence Imaging. SAE Technical Paper 2006-01-1518; 2006. 
Paper draft:

Implementation of Partially Premixed Combustion in a 2-stroke HSDI diesel engine fueled with gasoline

\section{Nomenclature}

\begin{tabular}{|c|c|}
\hline $\begin{array}{l}\text { aTDC } \\
\text { (A/F)St }\end{array}$ & $\begin{array}{l}\text { After Top Dead Centre } \\
\text { Stoichiometric Air to Fuel ratio }\end{array}$ \\
\hline BDC & Bottom Dead Centre \\
\hline CA10 & Crank angle for $10 \%$ of fuel burnt \\
\hline CA50 & Crank angle for $50 \%$ of fuel burnt \\
\hline cad & Crankangle degree \\
\hline CDC & Conventional diesel combustion \\
\hline CI & Compression ignition \\
\hline $\mathbf{C N}$ & Cetane number \\
\hline$\Delta \mathbf{P}$ & Pressure difference between intake and exhaust ports \\
\hline $\mathrm{dP} / \mathrm{damax}$ & Maximum pressure gradient \\
\hline EGR & Exhaust Gas Recirculation \\
\hline EoI & End of injection \\
\hline EVO & Exhaust Valve Opening (angle) \\
\hline HCCI & Homogeneous Charge Compression Ignition \\
\hline HD & Heavy duty \\
\hline HSDI & High Speed Direct Injection \\
\hline ID & Ignition delay \\
\hline IGR & Internal Gas Recirculation \\
\hline IMEP & Indicated Mean Effective Pressure \\
\hline IVC & Intake Valve Closing (angle) \\
\hline isfc & Indicated specific fuel consumption \\
\hline isfccorr & $\begin{array}{l}\text { Estimated "corrected" isfc considering energy consumption of the air } \\
\text { management devices (turbocharger and supercharger) }\end{array}$ \\
\hline NIST & National Institute of Standards and Technology \\
\hline PCCI & Premixed Charge Compression Ignition \\
\hline $\mathbf{P}_{\text {in }} / \mathbf{P}_{\text {ex }}$ & Intake / Exhaust pressure \\
\hline $\mathbf{P}_{\max }$ & Maximun cylinder pressure \\
\hline PPC & Partially Premixed Combustion \\
\hline Prail & Injection rail pressure \\
\hline$\phi$ cyl & Effective cylinder equivalence ratio \\
\hline RoHR & Rate of Heat Release \\
\hline RON & Research Octane Number \\
\hline SoC & Start of combustion \\
\hline SoE & Start of energizing (injector signal) \\
\hline SoI & Start of injection \\
\hline$\sigma \mathbf{P}_{\max }$ & Coefficient of variation of maximum cylinder pressure \\
\hline бIMEP & Coefficient of variation of indicated mean effective pressure \\
\hline $\mathbf{T}_{\text {ad }}$ & Adiabatic flame temperature \\
\hline $\mathbf{T}_{\text {ad,max }}$ & Maximum adiabatic flame temperature \\
\hline TDC & Top Dead Centre \\
\hline $\mathbf{T}_{\text {IVC }}$ & Mean gas temperature at intake valve closing \\
\hline $\mathbf{t}_{\text {mix }}$ & Mixing time \\
\hline VVT & Variable Valve Timing \\
\hline $\mathbf{V V T}_{\text {in }}$ & Intake Variable Valve Timing \\
\hline $\mathbf{V V T}_{\mathbf{e x}}$ & Exhaust Variable Valve Timing \\
\hline $\mathbf{Y O}_{2}$ & Oxygen concentration in the cylinder \\
\hline $\mathbf{Y O}_{2, \mathrm{IVC}}$ & Oxygen concentration at the intake valve closing angle \\
\hline YO2,EVo & Oxygen concentration at the exhaust valve opening angle \\
\hline$\eta_{\text {comb }}$ & Combustion efficiency \\
\hline$\eta_{\text {indicated }}$ & Indicated efficiency \\
\hline
\end{tabular}




\section{List of Figures}

1. Lifts crank angle for intake and exhaust valves 30

2. Layout of the engine test cell 31

3. Validation of the 1D spray model against experimental results in terms of spray 32 angle and penetration for a) $\mathrm{P}_{\text {rail }} 400$ bar and b) $\mathrm{P}_{\text {rail }} 800$ bar.

4. Combustion characteristics for $\mathrm{P}_{\text {rail }} 400$ and 600 bar.

a) Cylinder mean gas temperature, b) cylinder pressure, c) rate of heat release

5. Combustion characteristics for $\mathrm{P}_{\text {rail }} 400$ and 600 bar.

a) Max. cylinder pressure and $\sigma \mathrm{P}_{\max }, \mathrm{b}$ ) maximum pressure rise rate and $\sigma \mathrm{IMEP}$

6. Combustion characteristics for $\mathrm{P}_{\text {rail }} 400$ and 600 bar.

a) Mixing time and ignition delay, b) combustion angles CA10 and CA50

7. Mixing conditions for $\mathrm{P}_{\text {rail }} 400$ and $600 \mathrm{bar}$.

a) Maximum local equivalence ratio, b) fuel distribution at SoC

8. Exhaust emissions and efficiency for $\mathrm{P}_{\text {rail }} 400$ and 600 bar.

a) $\mathrm{NO}_{\mathrm{x}}$ and smoke, b) $\mathrm{HC}$ and $\left.\mathrm{CO}, \mathrm{c}\right) \eta_{\text {comb }}$ and $\eta_{\text {indicated }}$

9. Combustion characteristics for EGR 0\% and 14\%.

a) Cylinder mean gas temperature, b) cylinder pressure, c) rate of heat release.

10. Combustion characteristics for EGR 0\% and 14\%.

a) Max. cylinder pressure and $\sigma \mathrm{P}_{\max }$, b) maximum pressure rise rate and $\sigma \mathrm{IMEP}$

11. Combustion characteristics for EGR $0 \%$ and $14 \%$.

a) Mixing time and ignition delay, b) combustion angles CA10 and CA50

12. Mixing conditions for EGR $0 \%$ and $14 \%$.

a) Maximum local equivalence ratio, b) fuel distribution at $\mathrm{SoC}$

13. $\mathrm{T}_{\mathrm{ad}}$ and $\mathrm{NO}_{\mathrm{X}}$ analysis for EGR $0 \%$ and $14 \%$. a) $\mathrm{T}_{\mathrm{ad}} \mathrm{Vs}$ crankangle, b) $\mathrm{T}_{\mathrm{ad} \text {,max }} \mathrm{Vs}$ $\mathrm{NO}_{\mathrm{x}}$.

14. Exhaust emissions and efficiency for EGR $0 \%$ and $14 \%$.

a) $\mathrm{NO}_{\mathrm{X}}$ and smoke, b) $\mathrm{HC}$ and $\left.\mathrm{CO}, \mathrm{c}\right) \eta_{\text {comb }}$ and $\eta_{\text {indicated }}$

15. Combustion characteristics for EGR 0\% and 25\%.

a) Cylinder mean gas temperature, b) cylinder pressure, c) rate of heat release.

16. Combustion characteristics for EGR $0 \%$ and $25 \%$.

a) Max. cylinder pressure and $\left.\sigma \mathrm{P}_{\max }, \mathrm{b}\right)$ maximum pressure rise rate and $\sigma \mathrm{IMEP}$

17. Combustion characteristics for EGR $0 \%$ and $25 \%$.

a) Mixing time and ignition delay, b) combustion angles CA10 and CA50

18. Mixing conditions for EGR $0 \%$ and $25 \%$.

a) Maximum local equivalence ratio, b) fuel distribution at $\mathrm{SoC}$

19. $\mathrm{T}_{\text {ad }}$ and $\mathrm{NO}_{\mathrm{x}}$ analysis for EGR $0 \%$ and $25 \%$. a) $\mathrm{T}_{\mathrm{ad}} \mathrm{Vs}$ crankangle b) $\mathrm{T}_{\mathrm{ad} \text {,max }} \mathrm{vs}$ $\mathrm{NO}$.

20. Exhaust emissions and efficiency for EGR 0\% and 25\%.

a) $\mathrm{NO}_{\mathrm{x}}$ and smoke, b) $\mathrm{HC}$ and $\left.\mathrm{CO}, \mathrm{c}\right) \eta_{\text {comb }}$ and $\eta_{\text {indicated. }}$ 


\section{Paper draft:}

Implementation of Partially Premixed Combustion in a 2-stroke HSDI diesel engine fueled with gasoline

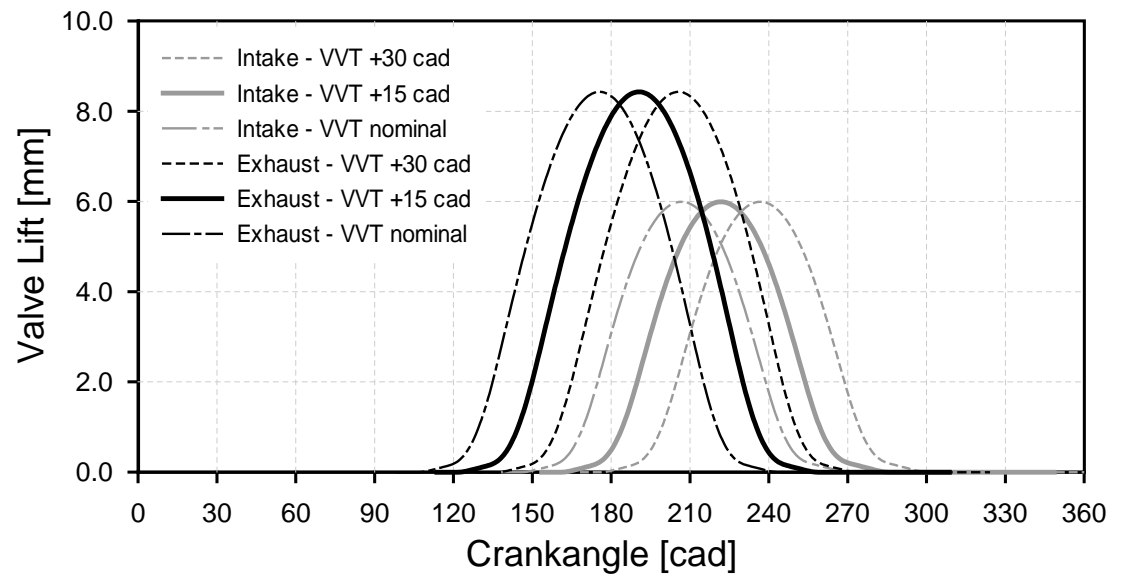

Fig. 1: Lifts for intake and exhaust valves. 
Paper draft:

Implementation of Partially Premixed Combustion in a 2-stroke HSDI diesel engine fueled with gasoline

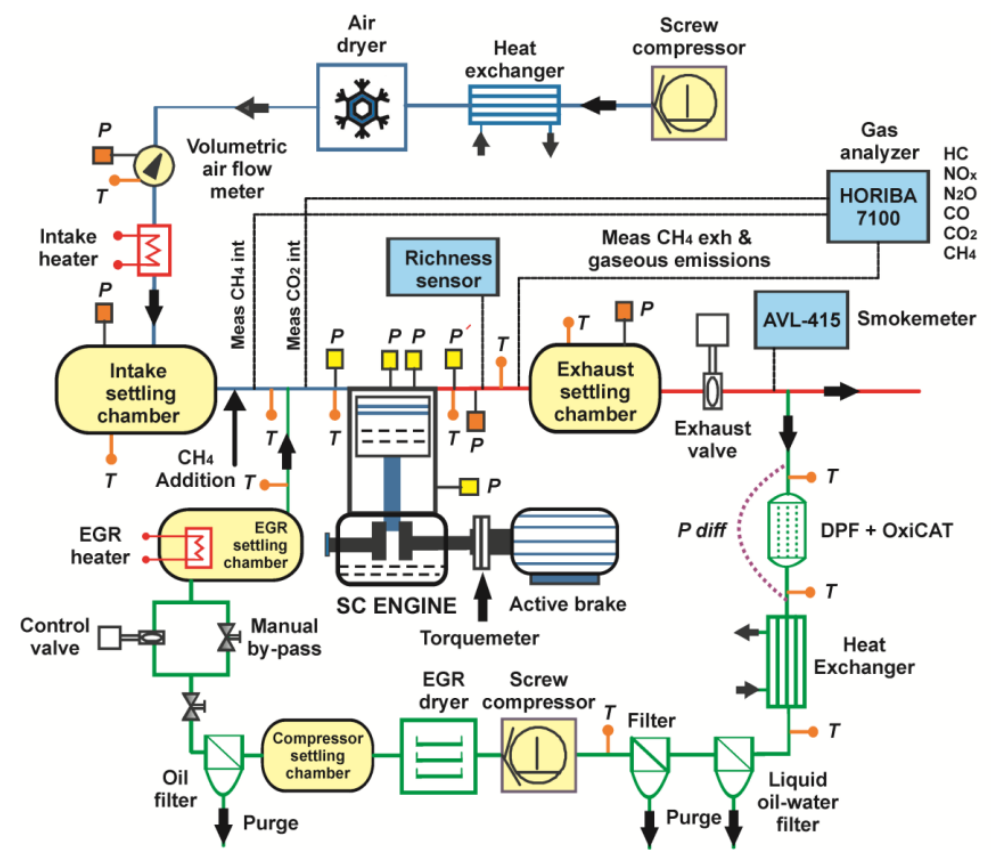

Fig. 2: Layout of the engine test cell 
Paper draft:

Implementation of Partially Premixed Combustion in a 2-stroke HSDI diesel engine fueled with gasoline

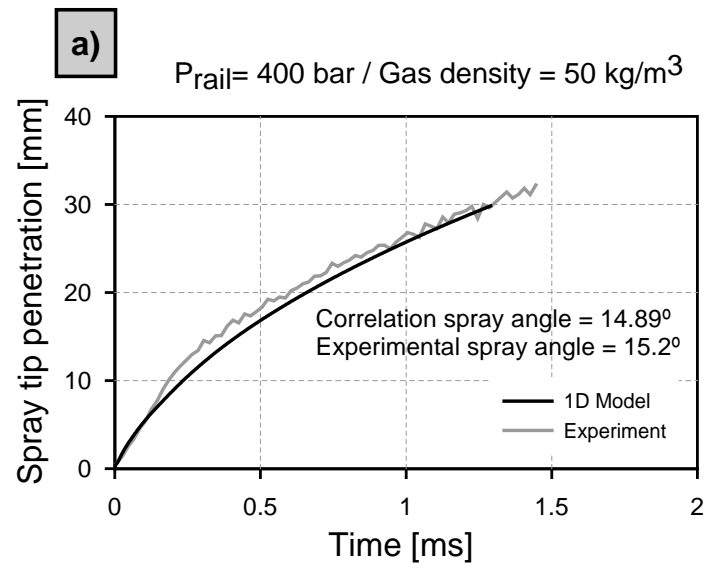

\section{b)}

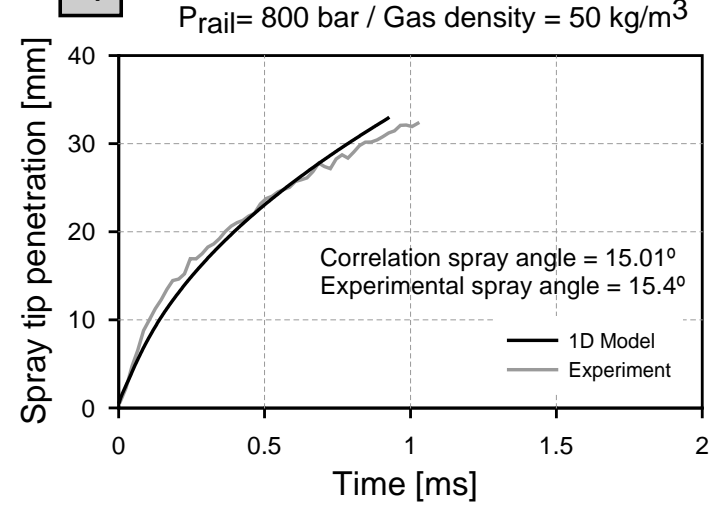

Fig. 3: Validation of the 1D spray model against experimental results in terms of spray angle and penetration for a) $P_{\text {rail }} 400$ bar and b) $P_{\text {rail }} 800$ bar. 
Paper draft:

Implementation of Partially Premixed Combustion in a 2-stroke HSDI diesel engine fueled with gasoline
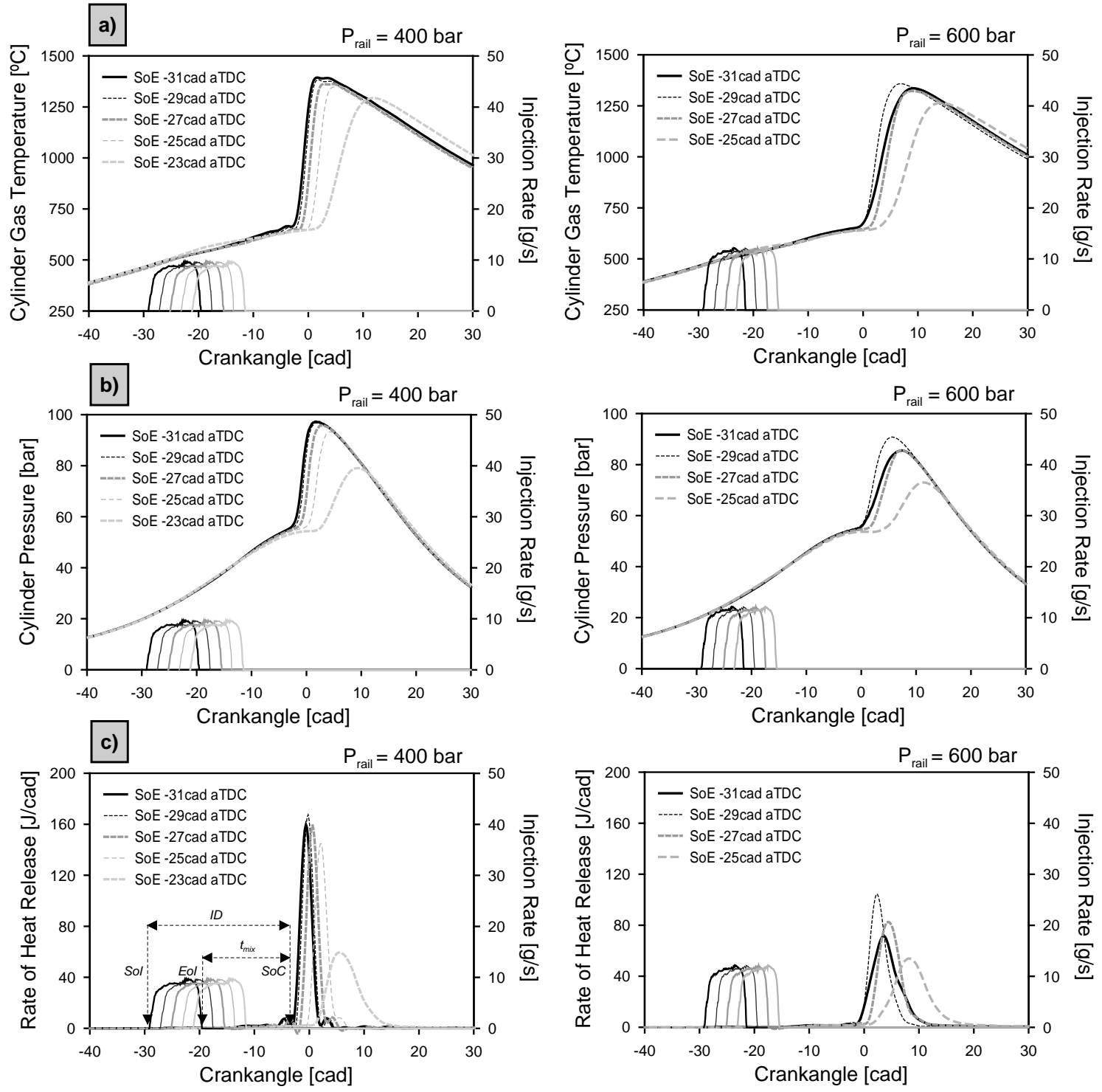

Fig. 4: Combustion characteristics for $P_{\text {rail }} 400$ and 600 bar. a) Cylinder mean gas temperature, b) cylinder pressure, c) rate of heat release. 
Paper draft:

Implementation of Partially Premixed Combustion in a 2-stroke HSDI diesel engine fueled with gasoline

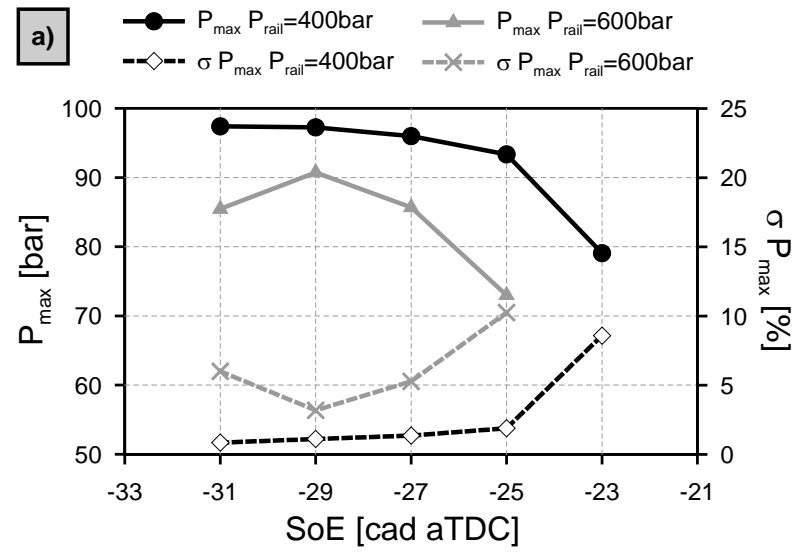

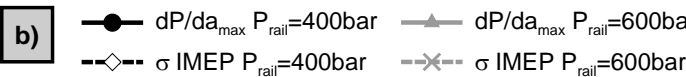

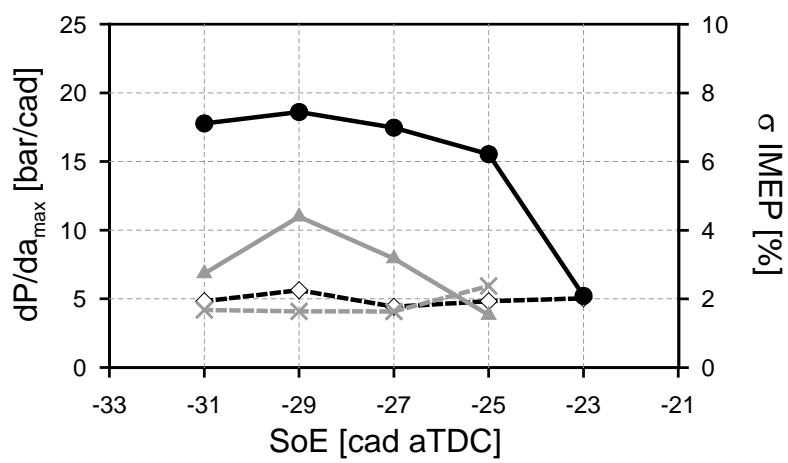

Fig. 5: Combustion characteristics for $\mathrm{P}_{\text {rail }} 400$ and 600 bar. a) Max. cylinder pressure and $\sigma \mathrm{P}_{\max }, \mathrm{b}$ ) maximum pressure rise rate and $\sigma \mathrm{IMEP}$. 
Paper draft:

Implementation of Partially Premixed Combustion in a 2-stroke HSDI diesel engine fueled with gasoline
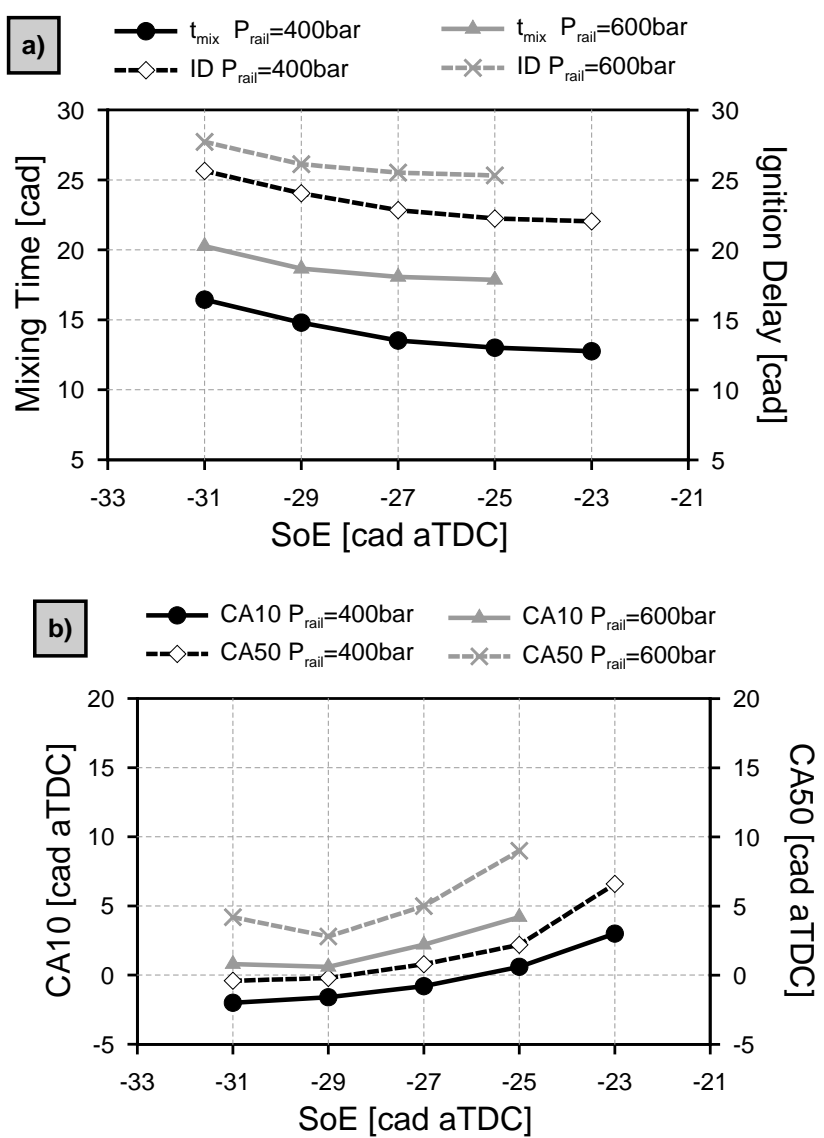

Fig. 6: Combustion characteristics for $P_{\text {rail }} 400$ and 600 bar. a) Mixing time and ignition delay, b) combustion angles CA10 and CA50. 

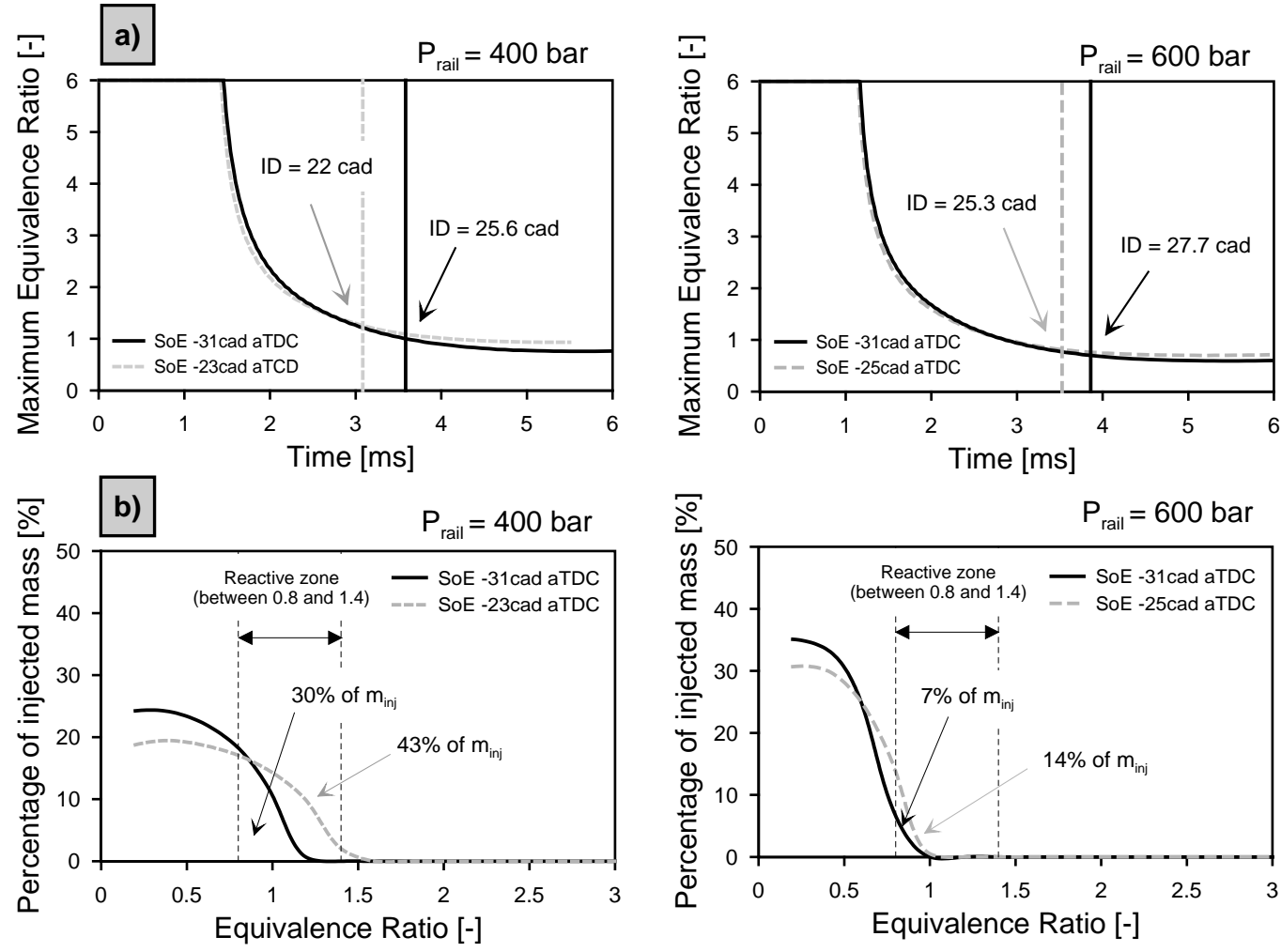

Fig. 7: Mixing conditions for $\mathrm{P}_{\text {rail }} 400$ and 600 bar. a) Maximum local equivalence ratio, b) fuel distribution at SoC. 
Paper draft:

Implementation of Partially Premixed Combustion in a 2-stroke HSDI diesel engine fueled with gasoline
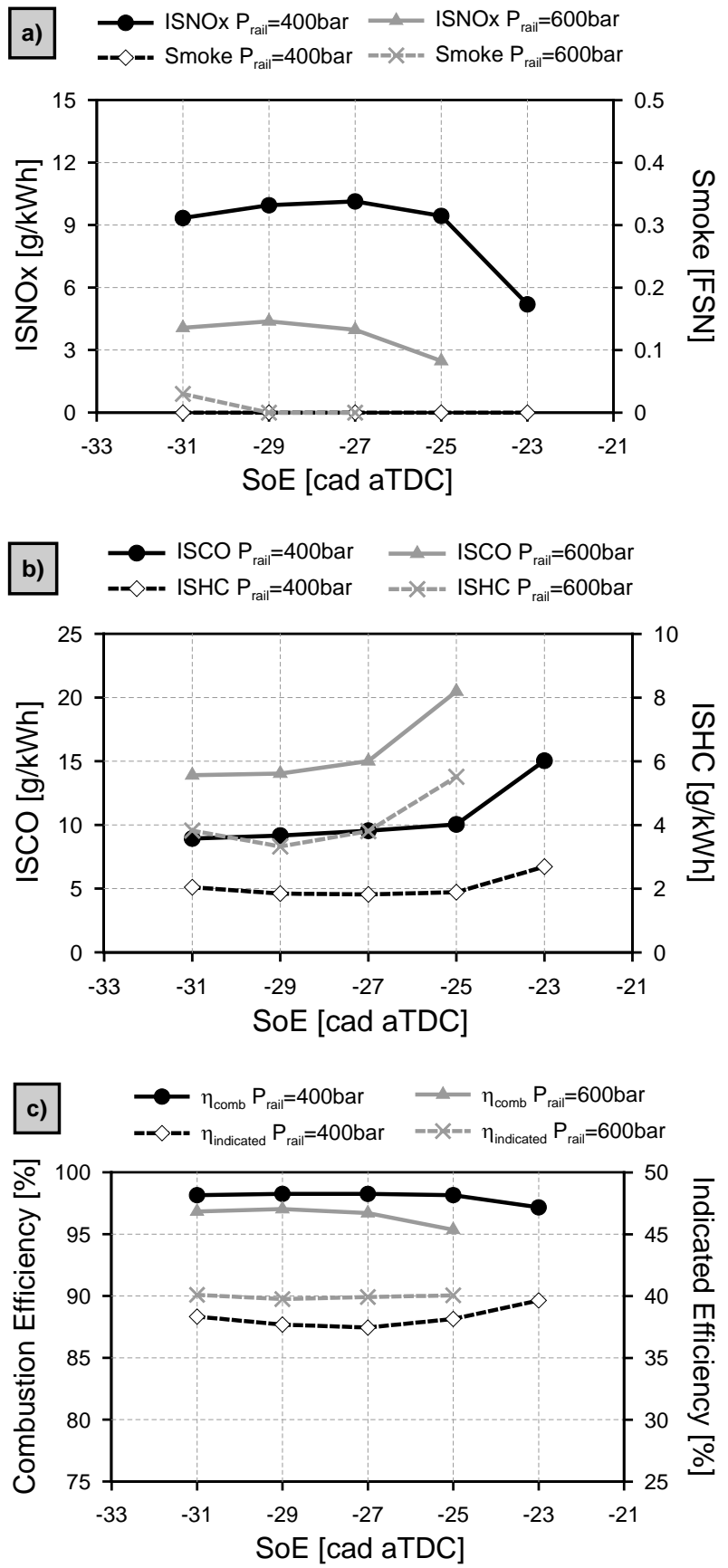

Fig. 8: Exhaust emissions and efficiency for $\mathrm{P}_{\text {rail }} 400$ and 600 bar. a) $\mathrm{NO}_{\mathrm{X}}$ and soot, b) $\mathrm{HC}$ and $\mathrm{CO}, \mathrm{c}) \eta_{\mathrm{comb}}$ and $\eta_{\text {indicated. }}$ 

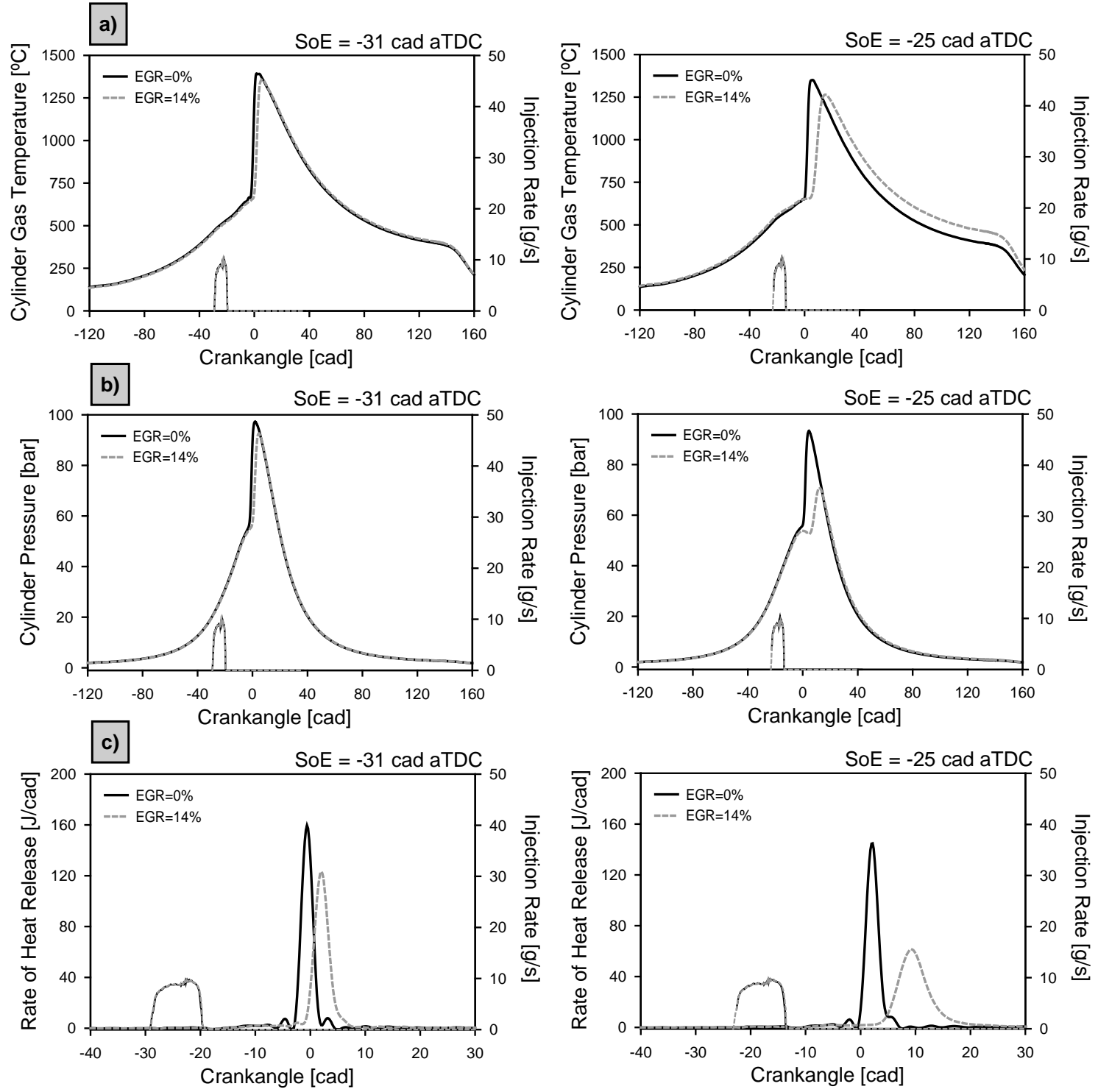

Fig. 9: Combustion characteristics for EGR 0\% and 14\%. a) Cylinder mean gas temperature, b) cylinder pressure, c) rate of heat release. 
Paper draft:

Implementation of Partially Premixed Combustion in a 2-stroke HSDI diesel engine fueled with gasoline

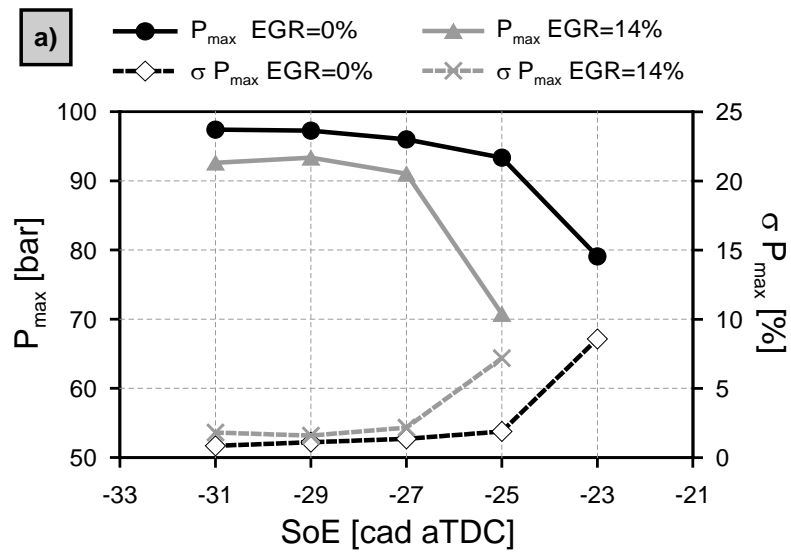

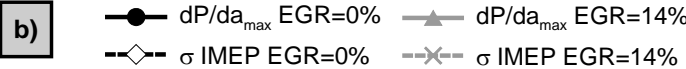

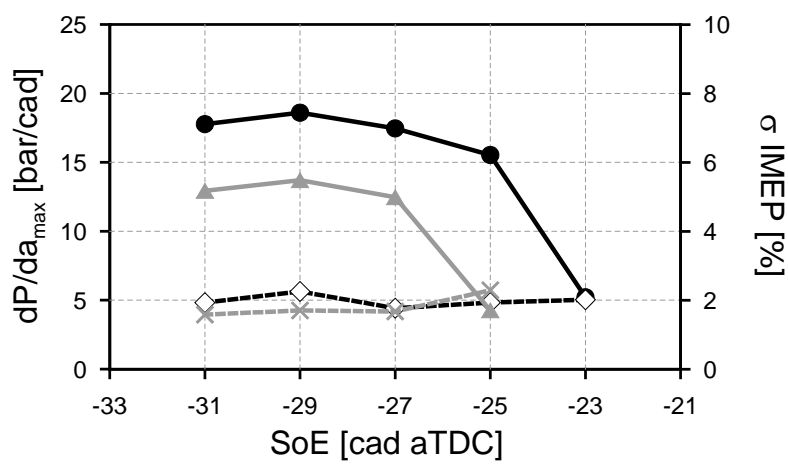

Fig. 10: Combustion characteristics for EGR 0\% and 14\%. a) Max. cylinder pressure and $\left.\sigma \mathrm{P}_{\max }, \mathrm{b}\right)$ maximum pressure rise rate and $\sigma \mathrm{IMEP}$. 
Paper draft:

Implementation of Partially Premixed Combustion in a 2-stroke HSDI diesel engine fueled with gasoline

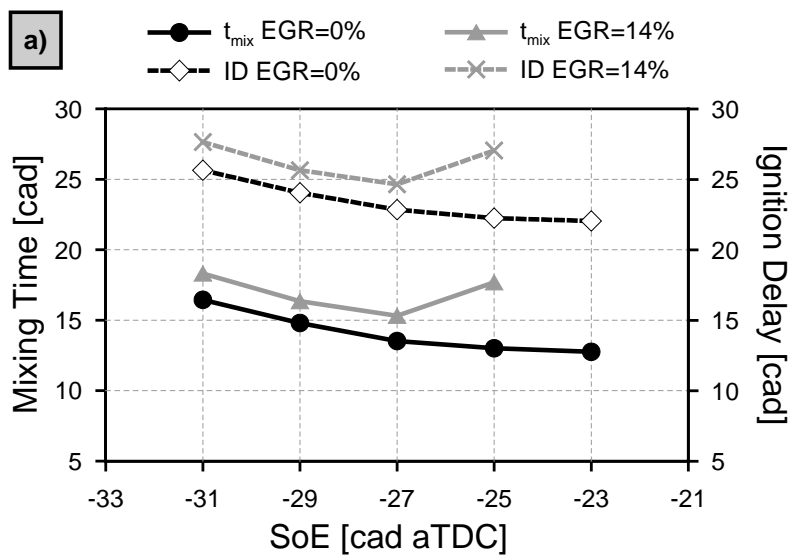

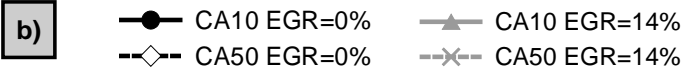

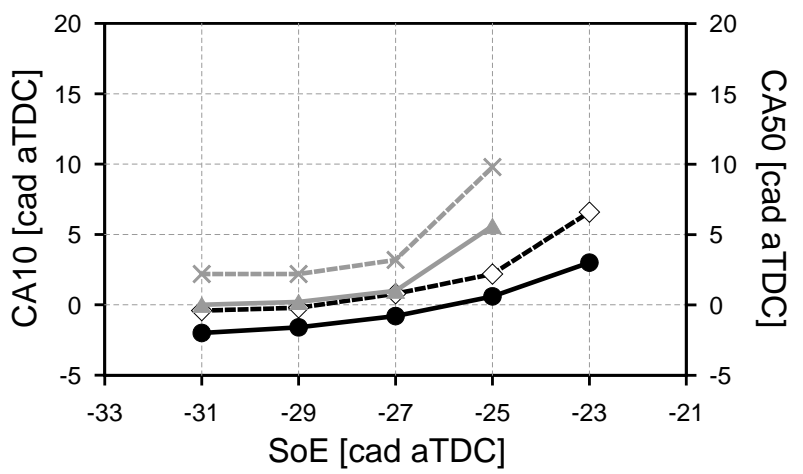

Fig. 11: Combustion characteristics for EGR 0\% and 14\%. a) Mixing time and ignition delay, b) combustion angles CA10 and CA50. 

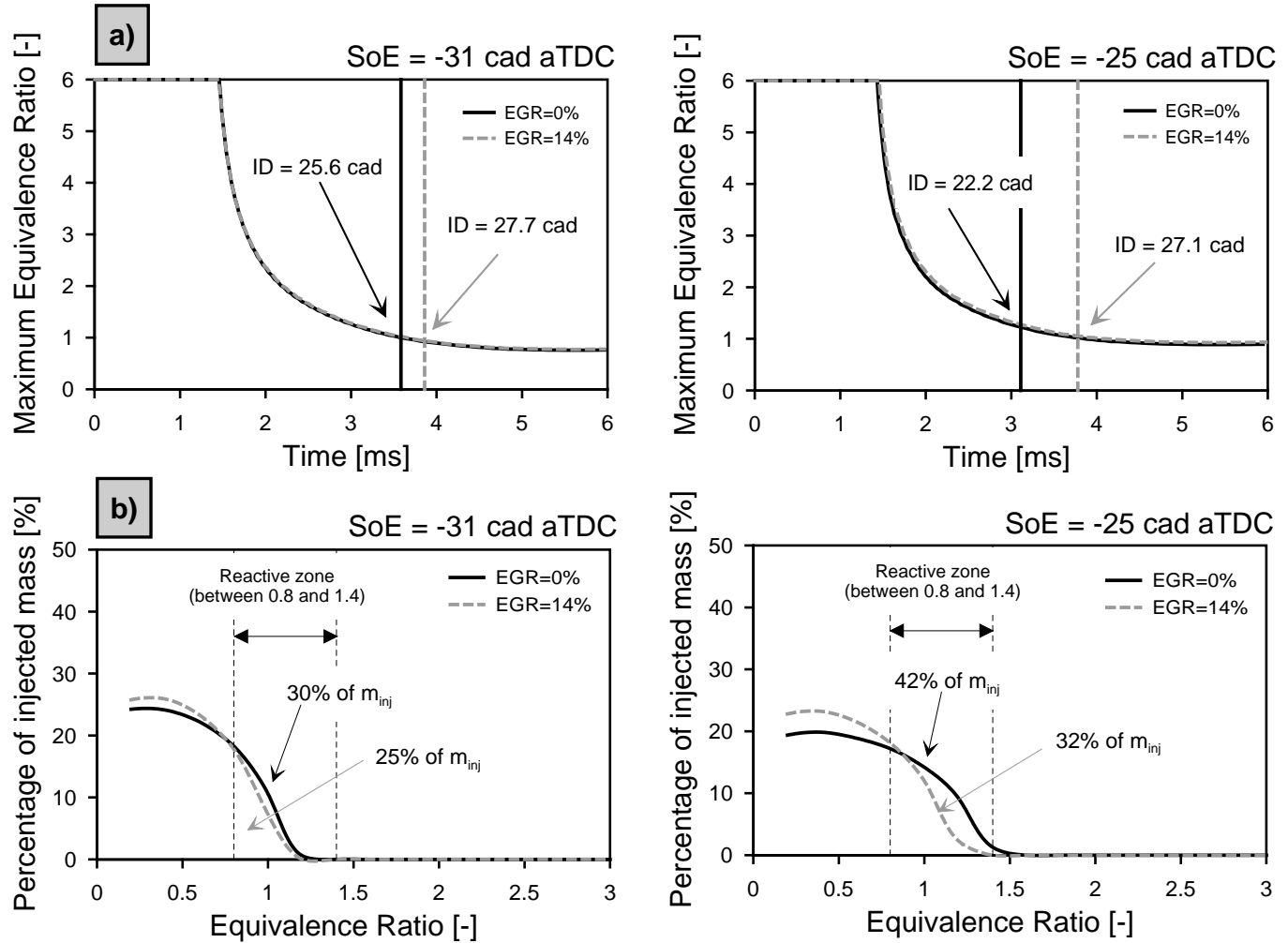

Fig. 12: Mixing conditions for EGR 0\% and 14\%. a) Maximum local equivalence ratio, b) fuel distribution at SoC. 
Paper draft:

Implementation of Partially Premixed Combustion in a 2-stroke HSDI diesel engine fueled with gasoline
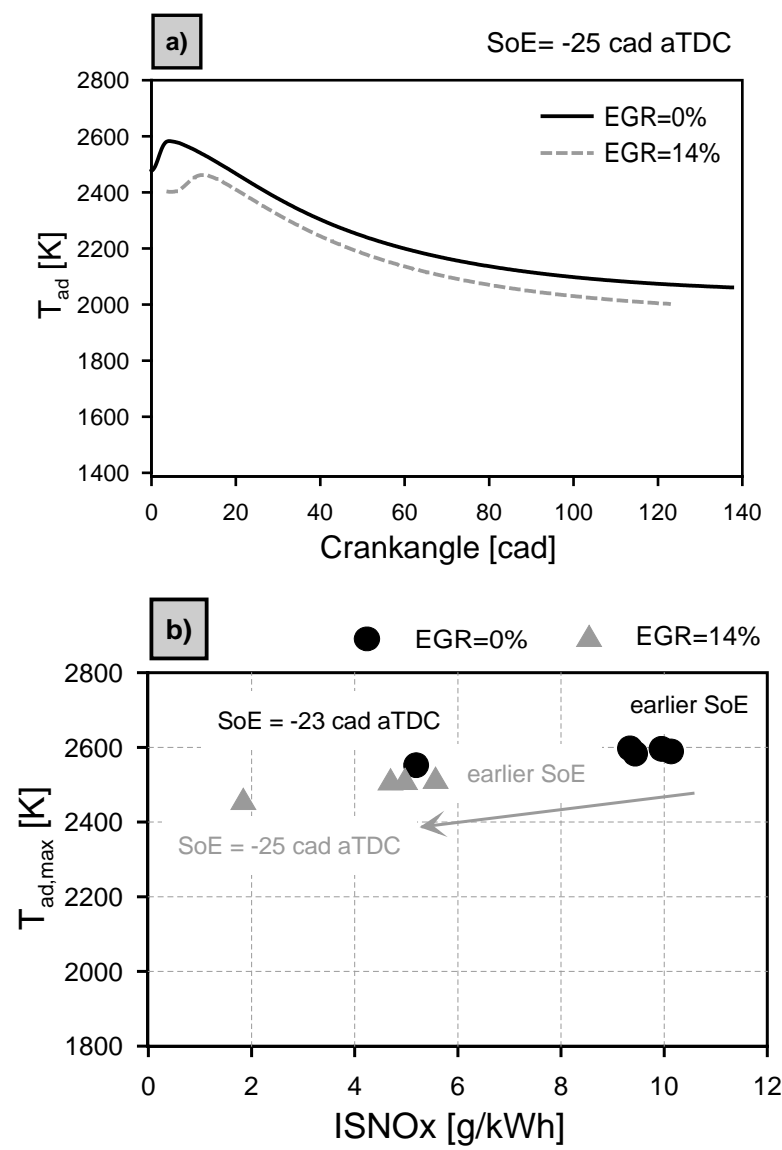

Fig. 13: $\mathrm{T}_{\mathrm{ad}}$ and $\mathrm{NO}$ x analysis for EGR $0 \%$ and $14 \%$. a) $\mathrm{T}_{\mathrm{ad}} \mathrm{Vs}$ crankangle, b) $\mathrm{T}_{\mathrm{ad}}$,max $\mathrm{vs}$ $\mathrm{NO}_{\mathrm{X}}$. 
Paper draft:

Implementation of Partially Premixed Combustion in a 2-stroke HSDI diesel engine fueled with gasoline

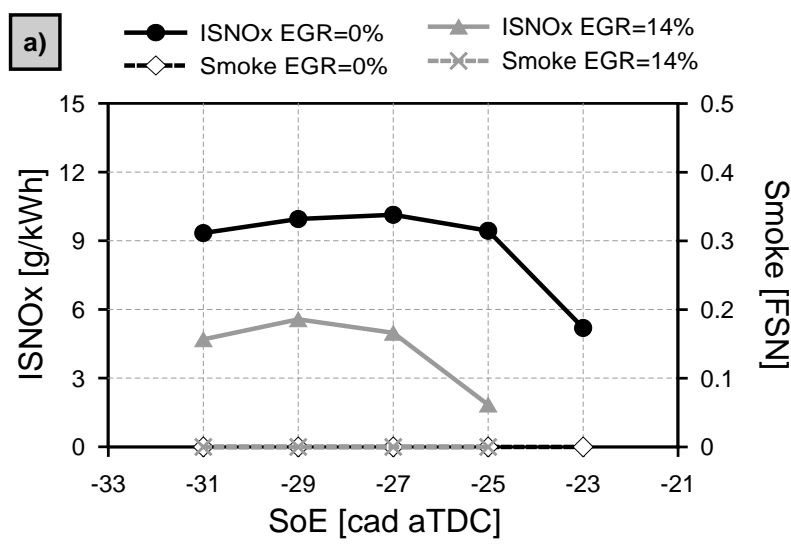

b) - ISCO EGR=0\% - ISCO EGR=14\%

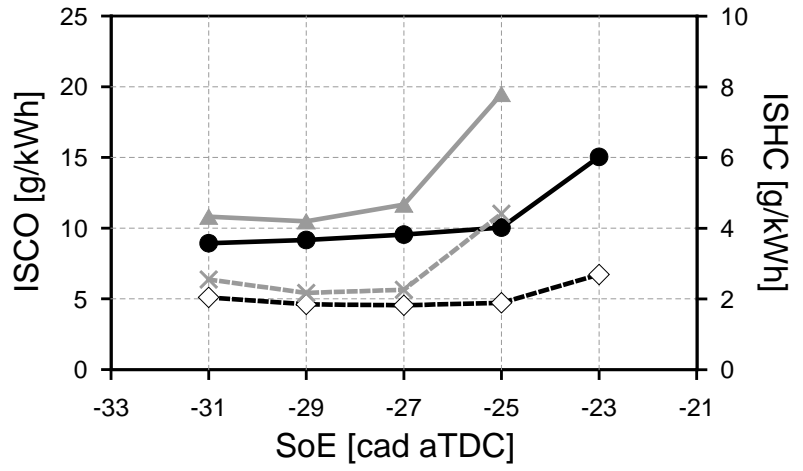

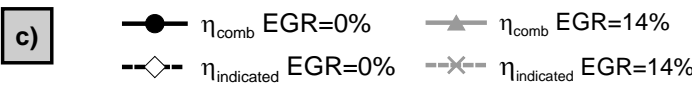

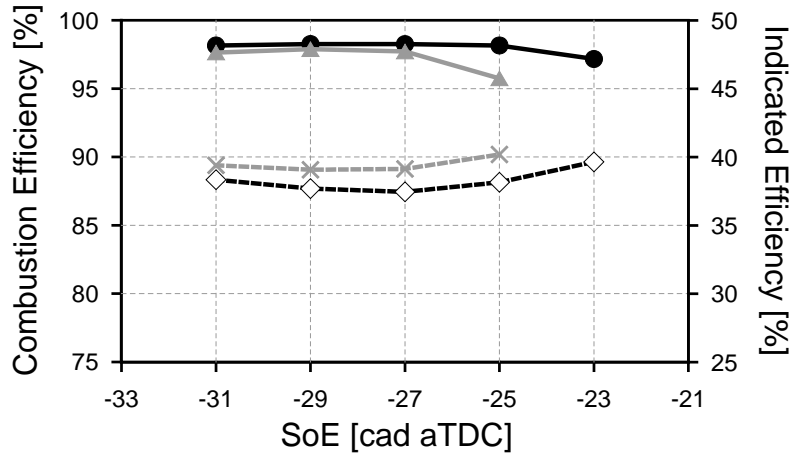

Fig. 14: Exhaust emissions and efficiency for EGR 0\% and 14\%. a) $\mathrm{NO}_{\mathrm{X}}$ and smoke, b) $\mathrm{HC}$ and $\mathrm{CO}, \mathrm{c}) \eta_{\text {comb }}$ and $\eta_{\text {indicated. }}$ 

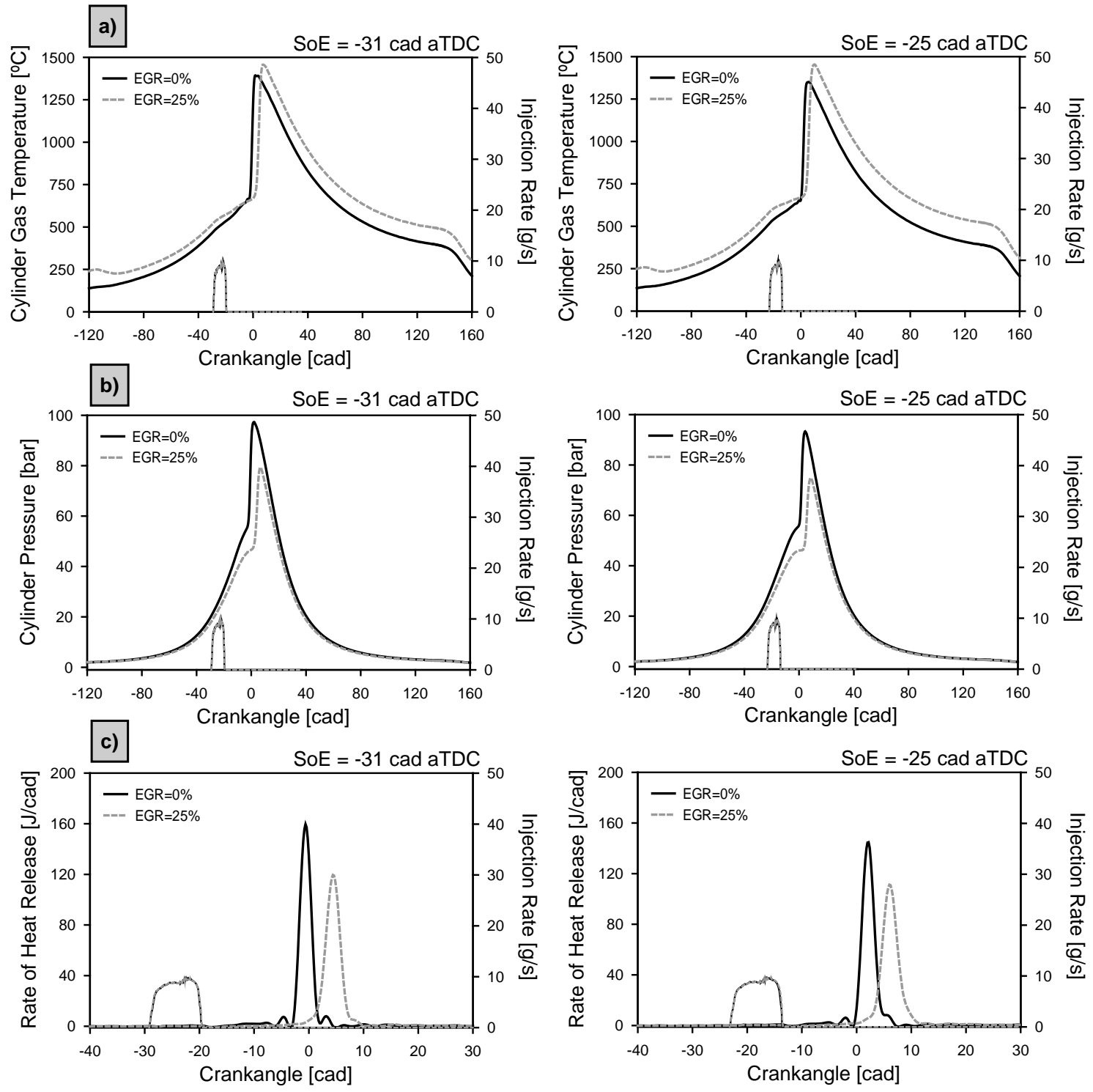

Fig. 15: Combustion characteristics for EGR 0\% and 25\%. a) Cylinder mean gas temperature, b) cylinder pressure, c) rate of heat release. 
Paper draft:

Implementation of Partially Premixed Combustion in a 2-stroke HSDI diesel engine fueled with gasoline
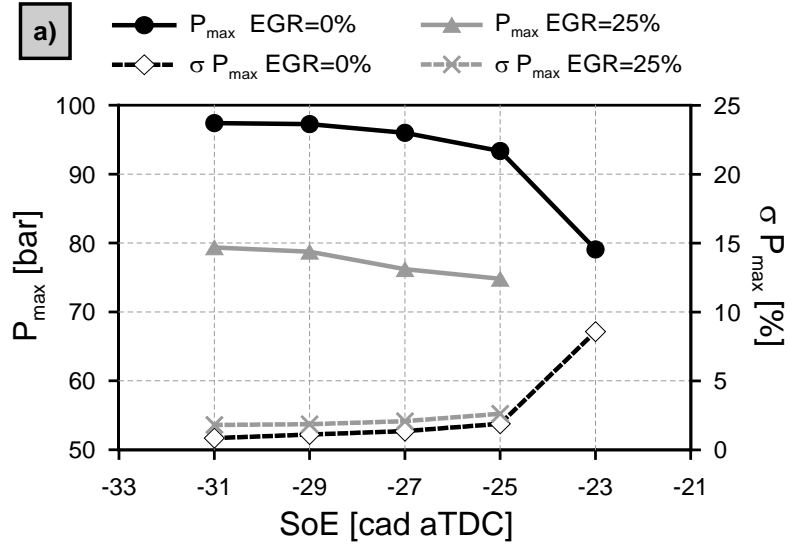

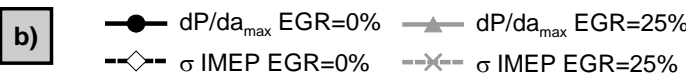

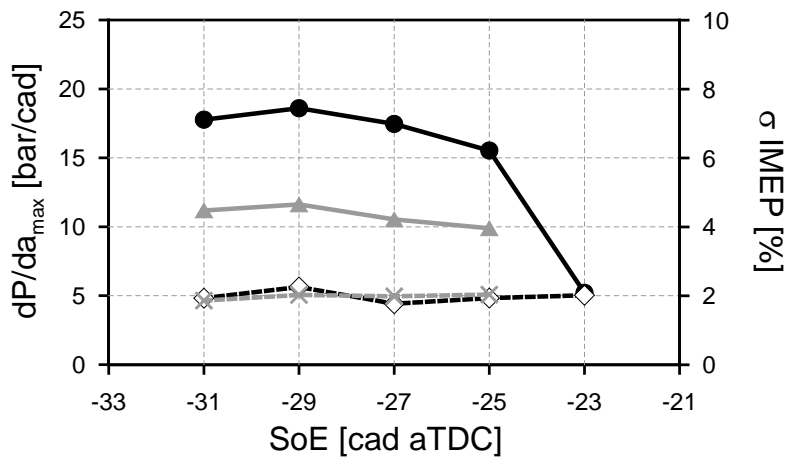

Fig. 16: Combustion characteristics for EGR 0\% and 25\%. a) Max. cylinder pressure and $\left.\sigma \mathrm{P}_{\max }, \mathrm{b}\right)$ maximum pressure rise rate and $\sigma \mathrm{IMEP}$. 
Paper draft:

Implementation of Partially Premixed Combustion in a 2-stroke HSDI diesel engine fueled with gasoline

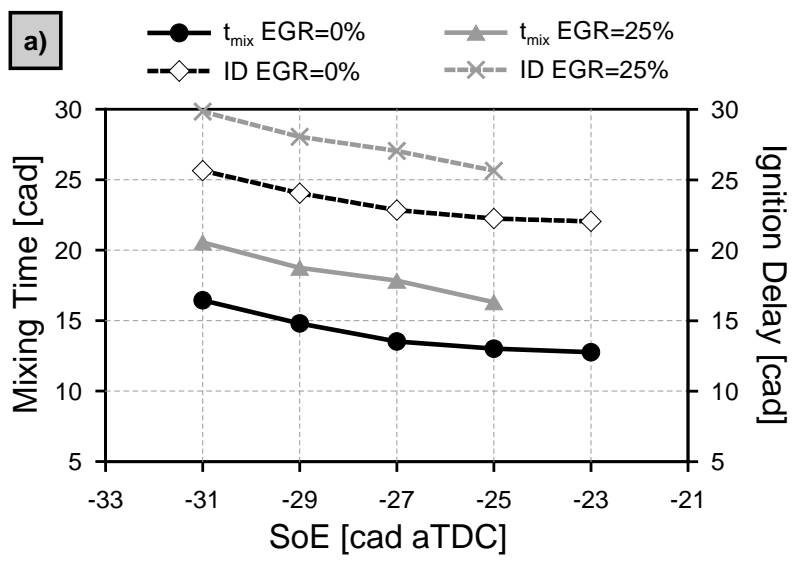

b) $\longrightarrow$ CA10 EGR=0\% - CA50 EGR=0\%

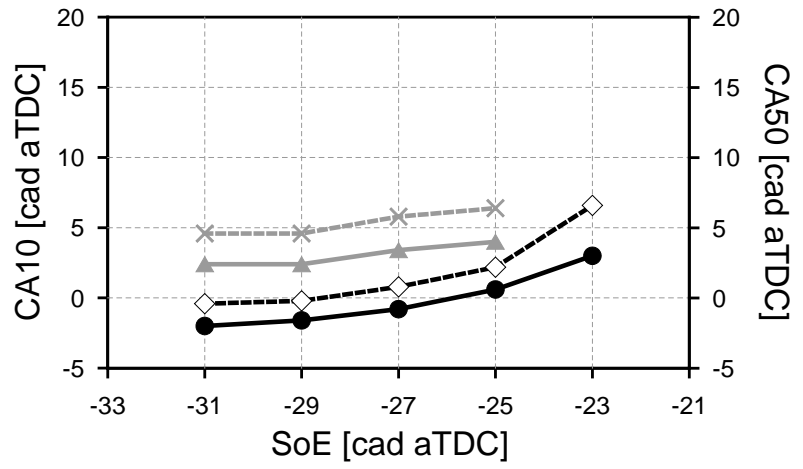

Fig. 17: Combustion characteristics for EGR 0\% and 25\%. a) Mixing time and ignition delay, b) combustion angles CA10 and CA50. 

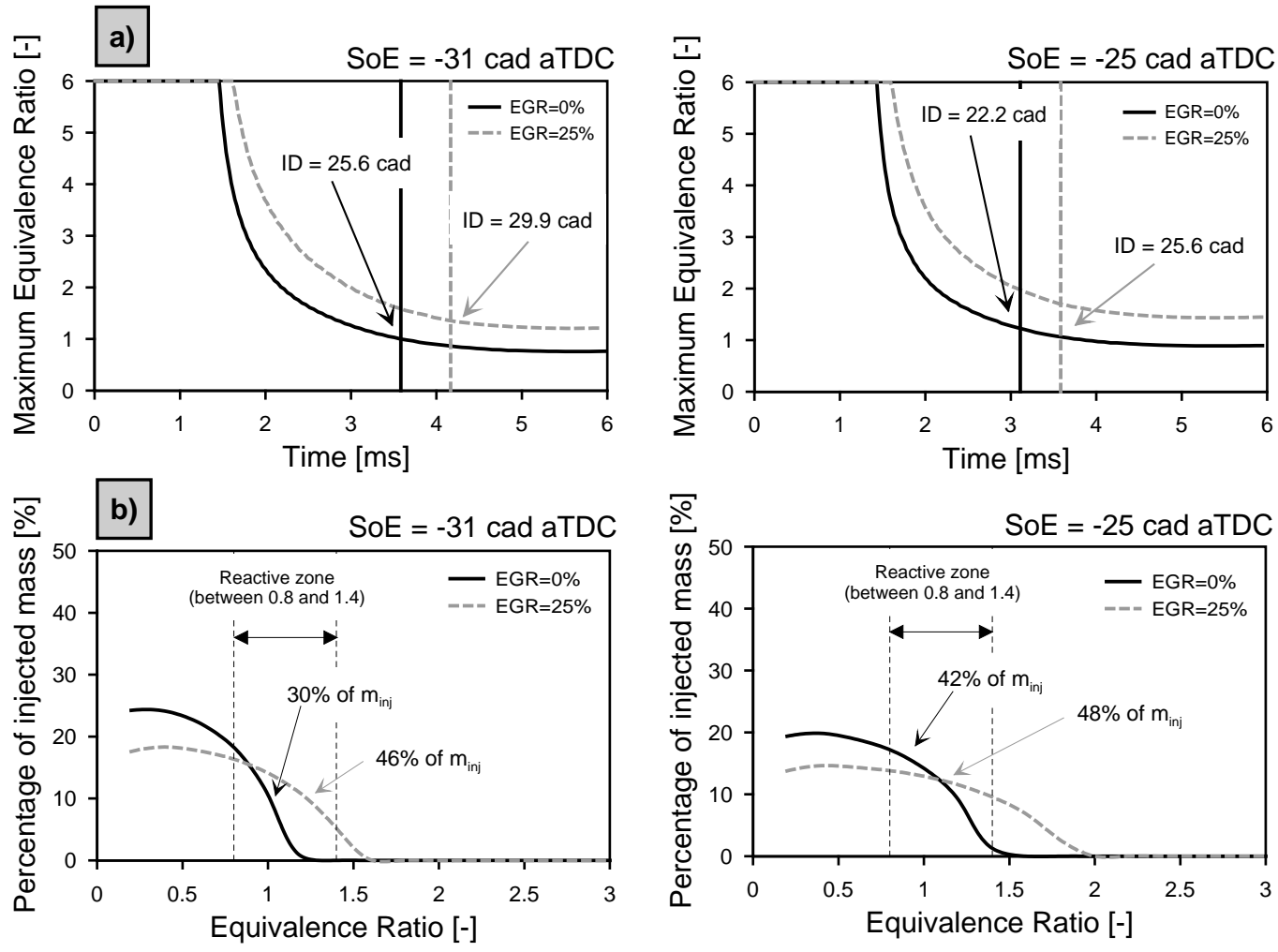

Fig. 18: Mixing conditions for EGR 0\% and 25\%. a) Maximum local equivalence ratio, b) fuel distribution at SoC. 
Paper draft:

Implementation of Partially Premixed Combustion in a 2-stroke HSDI diesel engine fueled with gasoline
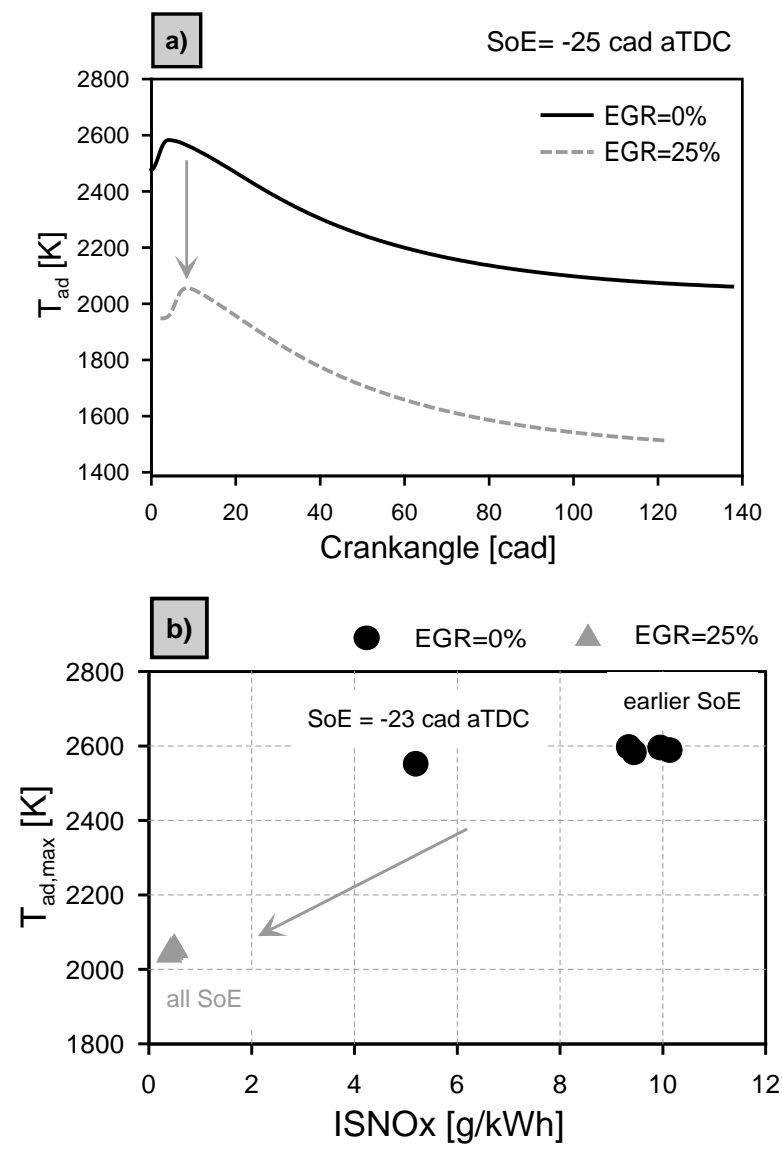

Fig. 19: $\mathrm{T}_{\mathrm{ad}}$ and $\mathrm{NO}_{\mathrm{x}}$ analysis for EGR $0 \%$ and $25 \%$. a) $\mathrm{T}_{\mathrm{ad}} \mathrm{Vs}$ crankangle $\mathrm{b}$ ) $\mathrm{T}_{\mathrm{ad}, \max } \mathrm{VS}$ $\mathrm{NO}$. 
Paper draft:

Implementation of Partially Premixed Combustion in a 2-stroke HSDI diesel engine fueled with gasoline

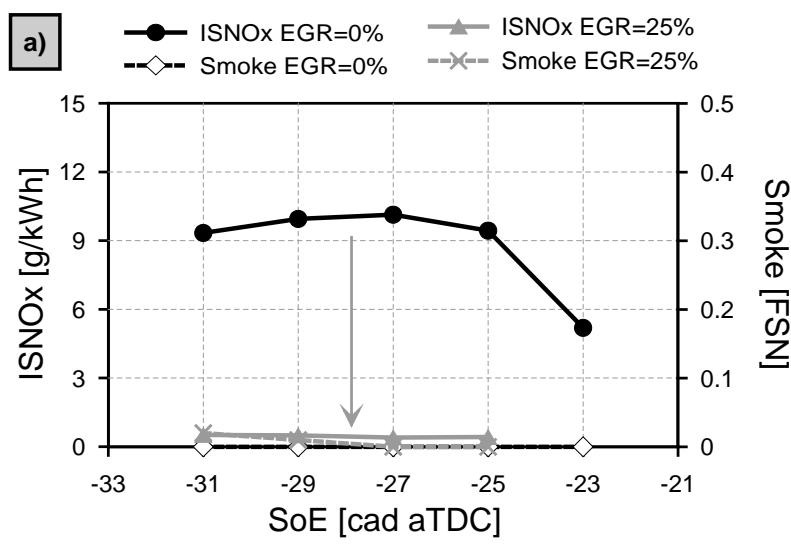

b) - ISCO EGR=0\% - ISCO EGR=25\%

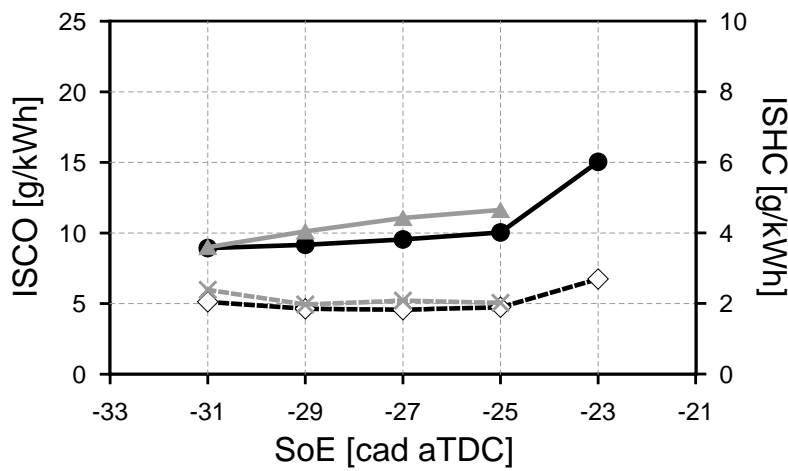

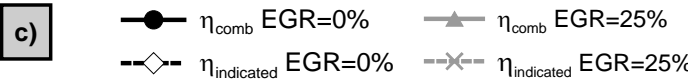

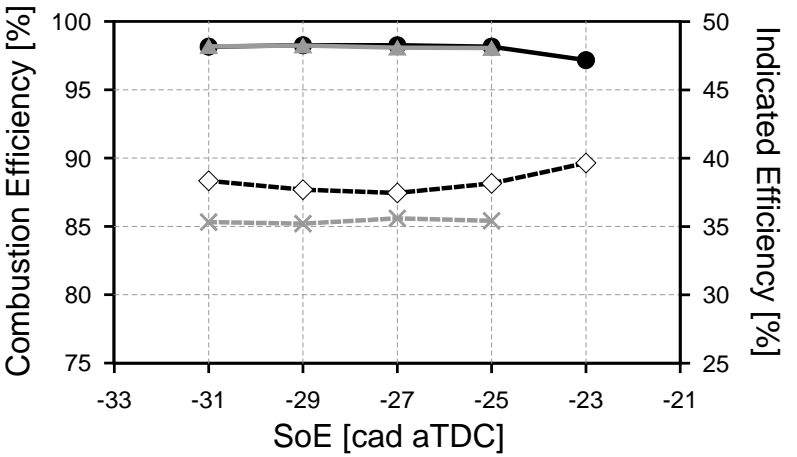

Fig. 20: Exhaust emissions and efficiency for EGR 0\% and 25\%. a) $\mathrm{NO}_{\mathrm{X}}$ and smoke, b) $\mathrm{HC}$ and $\mathrm{CO}, \mathrm{c}) \eta_{\mathrm{comb}}$ and $\eta_{\text {indicated. }}$ 
Paper draft:

Implementation of Partially Premixed Combustion in a 2-stroke HSDI diesel engine fueled with gasoline

\section{List of Tables}

1. Main engine specifications 51

2. Fuel properties 52

3. Accuracy of the instrumentation used in the research work 53

4. Experimental test conditions 54

5. Engine settings for experiments at $1200 \mathrm{rpm}-5$ bar IMEP 55 
Table 1: Main engine specifications

\begin{tabular}{|l|l|}
\hline Engine type & Two-stroke compression ignition \\
\hline Displacement & $\begin{array}{l}365 \mathrm{~cm}^{3} \text { (single cylinder Light } \\
\text { Duty engine) }\end{array}$ \\
\hline Bore $\times$ Stroke & $76 \mathrm{~mm} \times 80.5 \mathrm{~mm}$ \\
\hline Connecting Rod Length & $133.75 \mathrm{~mm}$ \\
\hline Geometric Compression Ratio & $\begin{array}{l}17.4 \text { (variable effective CR from } \\
13 \text { to } 8.8)\end{array}$ \\
\hline Number of valves/cylinder & 4 \\
\hline Type of scavenge & Poppet valves with scavenge loop \\
\hline Valvetrain & DOHC with VVA \\
\hline $\begin{array}{l}\text { Nominal intake valve timing } \\
\text { (set at VVT=0) }\end{array}$ & $\begin{array}{l}\text { IVO=161.9 cad aTDC } \\
\text { IVC=251.6 cad aTDC }\end{array}$ \\
\hline $\begin{array}{l}\text { Nominal exhaust valve timing } \\
\text { (set at VVT=0) }\end{array}$ & $\begin{array}{l}\text { EVO=122.6 cad aTDC } \\
\text { EVC=226.9 cad aTDC }\end{array}$ \\
\hline Fuel injection system & $\begin{array}{l}\text { Common rail diesel DI system } \\
\text { (maximum Prail }=1200 \text { bar when } \\
\text { injecting gasoline) }\end{array}$ \\
\hline $\begin{array}{l}\text { Injector nozzle } \\
\text { included spray angle }\end{array}$ \\
\hline
\end{tabular}


Table 2: Fuel properties

\begin{tabular}{|l|l|}
\hline Test fuel & $\begin{array}{l}\text { Regular unleaded RON 95 gasoline } \\
\text { with lubricity additive }\end{array}$ \\
\hline Research Octane Number (RON) & $\sim 95$ \\
\hline H/C ratio & $1.6974 \mathrm{~mol} / \mathrm{mol}$ \\
\hline O/C ratio & $0.0236 \mathrm{~mol} / \mathrm{mol}$ \\
\hline Oxygen content & $2.68 \%(\mathrm{~m} / \mathrm{m})$ \\
\hline$(\text { A/F })_{\text {St }}$ (by mass) & 14.16 \\
\hline LHV & $42.31 \mathrm{MJ} / \mathrm{kg}$ \\
\hline Density $\left(15^{\circ} \mathrm{C}\right)$ & $723.2 \mathrm{~kg} / \mathrm{m}^{3}$ \\
\hline Kinematic viscosity $\left(40^{\circ} \mathrm{C}\right)$ & $0.44 \mathrm{cSt}$ \\
\hline
\end{tabular}


Table 3: Accuracy of the instrumentation used in the research work.

\begin{tabular}{|l|l|l|}
\hline Sensor & Variable & Accuracy (\%) \\
\hline Piezoelectric & In-cylinder pressure & \pm 0.7 \\
\hline Thermocouples & Temperature of all fluids & \pm 0.35 \\
\hline Encoder & Engine speed & \pm 0.006 \\
\hline Exhaust gas analyzer & Exhaust emissions $\left(\mathrm{NO}_{\mathrm{X}}, \mathrm{CO}, \mathrm{HC}, \mathrm{O}_{2}\right)$ & \pm 2 \\
\hline Smoke meter & FSN & \pm 2 \\
\hline Piezoresistive & $\begin{array}{l}\text { Intake and exhaust pressure, in-cylinder } \\
\text { pressure at BDC }\end{array}$ & \pm 0.65 \\
\hline Torque meter & Torque & \pm 0.1 \\
\hline Fuel mass flow meter & Fuel mass & \pm 0.2 \\
\hline Air mass flow meter & Air mass & \pm 0.12 \\
\hline
\end{tabular}


Paper draft:

Implementation of Partially Premixed Combustion in a 2-stroke HSDI diesel engine fueled with gasoline

Table 4: Experimental test conditions

\begin{tabular}{|l|l|}
\hline Engine speed & $1200 \mathrm{rpm}$ \\
\hline IMEP & 5 bar (nominal test) \\
\hline Injected fuel quantity & $10.6 \mathrm{mg} /$ stroke (nominal test) \\
\hline Intake air temperature & $35^{\circ} \mathrm{C}$ \\
\hline Coolant temperature & $90^{\circ} \mathrm{C}$ \\
\hline Oil temperature & $90^{\circ} \mathrm{C}$ \\
\hline
\end{tabular}


Table 5: Engine settings for experiments at $1200 \mathrm{rpm}-5$ bar IMEP.

\begin{tabular}{|c|c|c|c|c|c|c|c|c|}
\hline Test & $\begin{array}{c}\mathrm{P}_{\text {in }} \\
{[\mathrm{bar}]}\end{array}$ & $\begin{array}{c}\mathrm{P}_{\mathrm{ex}} \\
{[\mathrm{bar}]}\end{array}$ & $\begin{array}{c}\text { EGR } \\
{[\%]}\end{array}$ & $\begin{array}{c}\mathrm{VVT}_{\text {in }} \\
{[\mathrm{cad}]}\end{array}$ & $\begin{array}{c}\mathrm{VVT}_{\text {ex }} \\
{[\mathrm{cad}]}\end{array}$ & $\begin{array}{c}\text { Overlap } \\
{[\mathrm{cad}]}\end{array}$ & $\begin{array}{c}\mathrm{P}_{\text {rail }} \\
{[\mathrm{bar}]}\end{array}$ & $\begin{array}{c}\text { SoE } \\
\text { [cad aTDC] }\end{array}$ \\
\hline 4.1 .1 & 1.8 & 1.55 & 0 & 0 & +15 & 80 & $\mathbf{4 0 0}$ & -31 to -23 \\
\hline 4.1 .2 & 1.8 & 1.55 & 0 & 0 & +15 & 80 & $\mathbf{6 0 0}$ & -31 to -23 \\
\hline 4.2 .1 & 1.8 & 1.55 & $\mathbf{1 4}$ & 0 & +15 & 80 & 400 & -31 to -23 \\
\hline 4.2 .2 & 1.8 & $\mathbf{1 . 6}$ & $\mathbf{2 5}$ & $+\mathbf{1 0}$ & +15 & $\mathbf{7 0}$ & 400 & -31 to -23 \\
\hline
\end{tabular}

